\title{
Relationships between the surface concentration of particulate organic carbon and optical properties in the eastern South Pacific and eastern Atlantic Oceans
}

\author{
D. Stramski ${ }^{1}$, R. A. Reynolds ${ }^{1}$, M. Babin ${ }^{2,3}$, S. Kaczmarek ${ }^{4}$, M. R. Lewis ${ }^{5}$, R. Röttgers ${ }^{6}$, A. Sciandra ${ }^{2,3}$, M. Stramska ${ }^{7}$, \\ M. S. Twardowski ${ }^{8}$, B. A. Franz ${ }^{9}$, and H. Claustre ${ }^{2,3}$ \\ ${ }^{1}$ Marine Physical Lab., Scripps Institution of Oceanography, Univ. of California at San Diego, La Jolla, CA 92093-0238, USA \\ ${ }^{2}$ CNRS, UMR 7093, Laboratoire d'Océanographie de Villefranche (LOV), 06230 Villefranche-sur-mer, France \\ ${ }^{3}$ Université Pierre et Marie Curie-Paris6, UMR 7093, LOV, 06230 Villefranche-sur-mer, France \\ ${ }^{4}$ Institute of Oceanology, Polish Academy of Sciences, Powstanców Warszawy 55, 81-712 Sopot, Poland \\ ${ }^{5}$ Department of Oceanography, Dalhousie University, Halifax, NS, BH3 4J1, Canada \\ ${ }^{6}$ Institute for Coastal Research, GKSS Research Center, Geesthacht, Max-Planck-Str., 21502 Geesthacht, Germany \\ ${ }^{7}$ Center for Hydro-Optics \& Remote Sensing, San Diego State Univ., 6505 Alvarado Rd., San Diego, CA 92120, USA \\ ${ }^{8}$ Department of Research, WET Labs, Inc., 165 Dean Knauss Dr., Narragansett, RI 02882, USA \\ ${ }^{9}$ Science Applications International Corporation, NASA Goddard Space Flight Center, Greenbelt, MD 20771, USA
}

Received: 12 September 2007 - Published in Biogeosciences Discuss.: 2 October 2007

Revised: 7 January 2008 - Accepted: 11 January 2008 - Published: 14 February 2008

\begin{abstract}
We have examined several approaches for estimating the surface concentration of particulate organic carbon, POC, from optical measurements of spectral remotesensing reflectance, $R_{r s}(\lambda)$, using field data collected in tropical and subtropical waters of the eastern South Pacific and eastern Atlantic Oceans. These approaches include a direct empirical relationship between POC and the blue-to-green band ratio of reflectance, $R_{r s}\left(\lambda_{B}\right) / R_{r s}(555)$, and two-step algorithms that consist of relationships linking reflectance to an inherent optical property IOP (beam attenuation or backscattering coefficient) and POC to the IOP. We considered two-step empirical algorithms that exclusively include pairs of empirical relationships and two-step hybrid algorithms that consist of semianalytical models and empirical relationships. The surface POC in our data set ranges from about $10 \mathrm{mg} \mathrm{m}^{-3}$ within the South Pacific Subtropical Gyre to $270 \mathrm{mg} \mathrm{m}^{-3}$ in the Chilean upwelling area, and ancillary data suggest a considerable variation in the characteristics of particulate assemblages in the investigated waters. The POC algorithm based on the direct relationship between POC and $R_{r s}\left(\lambda_{B}\right) / R_{r s}(555)$ promises reasonably good performance in the vast areas of the open ocean covering different provinces
\end{abstract}

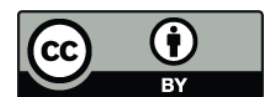

Correspondence to: D. Stramski (dstramski@ucsd.edu) from hyperoligotrophic and oligotrophic waters within subtropical gyres to eutrophic coastal upwelling regimes characteristic of eastern ocean boundaries. The best error statistics were found for power function fits to the data of POC vs. $R_{r s}(443) / R_{r s}(555)$ and POC vs. $R_{r s}(490) / R_{r s}(555)$. For our data set that includes over 50 data pairs, these relationships are characterized by the mean normalized bias of about $2 \%$ and the normalized root mean square error of about $20 \%$. We recommend that these algorithms be implemented for routine processing of ocean color satellite data to produce maps of surface POC with the status of an evaluation data product for continued work on algorithm development and refinements. The two-step algorithms also deserve further attention because they can utilize various models for estimating IOPs from reflectance, offer advantages for developing an understanding of bio-optical variability underlying the algorithms, and provide flexibility for regional or seasonal parameterizations of the algorithms.

\section{Introduction}

Optical measurements performed from various in situ and remote sensing platforms provide an effective tool for studying biogeochemically significant constituents of ocean waters. In comparison with traditional methods that require analysis of

Published by Copernicus Publications on behalf of the European Geosciences Union. 
discrete water samples, optical measurements allow significant extension of observational time and space scales through the use of instruments deployed on in-water vertical profiling systems, moorings, drifters, autonomous vehicles, as well as air-borne and space-borne platforms (Robinson, 2004; Myers and Miller, 2005; Twardowski et al., 2005).

In situ measurements of the beam attenuation coefficient have long been used to characterize bulk particulate properties, most notably the dry mass concentration of suspended particulate matter, SPM (Zaneveld, 1973; Baker and Lavelle, 1984; Gardner et al., 1985; Bishop, 1986, 1999; Spinrad, 1986). Relationships between ocean reflectance and SPM have also been investigated for the purpose of estimating SPM from remote sensing (Gordon and Morel, 1983; Stumpf and Pennock, 1989; Doxaran et al., 2002).

Similarly, it has long been recognized that optical measurements provide a useful proxy for the concentration of the primary pigment in phytoplankton, chlorophyll- $a$ (Chl- $a$ ). The development of bio-optical algorithms linking measurable optical properties to Chl- $a$ has been the focus of numerous studies over the last three decades. Field data have been used to examine empirical relationships between Chl- $a$ and inherent optical properties (IOPs) such as the absorption coefficient (e.g., Garver et al., 1994; Bricaud et al., 1995, 1998), the beam attenuation coefficient (e.g., Voss, 1992; Loisel and Morel, 1998), the scattering coefficient (e.g., Gordon and Morel, 1983; Loisel and Morel, 1998), and the backscattering coefficient (e.g., Reynolds et al., 2001; Stramska et al., 2006). Field measurements of Chl- $a$ and apparent optical properties (AOPs) such as ocean reflectance and the diffuse attenuation coefficient for downward irradiance have been also analyzed extensively for establishing bio-optical models and algorithms (e.g., Smith and Baker, 1978; Gordon and Morel, 1983; Morel, 1988; O'Reilly et al., 1998; Morel and Maritorena, 2001). Probably the single most studied bio-optical relationship in recent decades has been that linking surface Chl- $a$ to remote-sensing reflectance of the ocean. This has been driven by interest in the study of phytoplankton biomass and primary productivity from satellite remote sensing (e.g., Platt and Sathyendranath, 1988; Yoder et al., 1993; Antoine et al., 2005). Empirical relationships for estimating Chl- $a$ from reflectance are currently used for routine processing of global satellite imagery of ocean color (O'Reilly et al., 2000).

For studies of ocean biogeochemistry and its potential role in climate it is carbon, not chlorophyll, which is usually of most direct interest. The particulate organic carbon (POC) pool in the surface ocean, which includes autotrophic and heterotrophic organisms and biogenic detrital particles, represents one carbon reservoir of substantial interest. POC is a highly dynamic carbon pool and its variability is poorly characterized. Sinking of POC from surface waters is part of the biological pump that provides a mechanism for storing carbon in the deep ocean, a long-term sink for atmospheric $\mathrm{CO}_{2}$ (Volk and Hoffert, 1985; Longhurst and Har- rison, 1989). The knowledge of total POC and subsequent inference of the phytoplankton portion of POC is essential to the development of methods for estimating phytoplankton growth rates and carbon-based net primary production from satellite observations (Behrenfeld et al., 2005). Because the turnover time of carbon biomass is relatively short (1-2 weeks), satellite capabilities to monitor changes in particulate carbon pools can effectively aid in studies related to the biological pump.

Relationships between ocean optical properties and POC first appeared in the late 1980s. Morel (1988) demonstrated a relationship between the scattering coefficient at a light wavelength (in vacuo) $\lambda=550 \mathrm{~nm}, b(550)$, with Chl- $a$ and a relationship between POC and Chl- $a$, both obtained from a large data set collected in different oceanic regions. These two relationships suggested the existence of a nearly linear relationship between $b(550)$ and POC. Morel's data showed a general trend of covariation of POC with Chl- $a$ over 3 orders of magnitude range in Chl- $a$, but also at any given Chl- $a$ there existed a significant several-fold variation in the POC:Chl- $a$ ratio. Because this variability is difficult to predict, POC cannot be estimated directly from Chl- $a$ with consistently good accuracy. Linking POC to optics by converting SPM to POC through the use of SPM-specific optical coefficients such as the beam attenuation (Siegel et al., 1989) is also limited by large and difficult to predict variations in the conversion factors. Therefore, concurrent measurements of POC and optical parameters appear naturally as the most desirable approach for linking these variables.

Laboratory experiments with marine phytoplankton cultures suggest that the POC-specific scattering coefficient and the POC-specific beam attenuation coefficient (which is dominated by scattering) exhibit relatively small variations for a wide range of growth conditions (Stramski and Morel, 1990; Stramski and Reynolds, 1993). At the level of individual particles, the mechanism responsible for the relatively robust relationship between scattering and POC can be attributed to both a relation between the cellular carbon content and cell size (Verity et al., 1992; Montagnes et al., 1994) and a relation between the intracellular carbon concentration and refractive index of cells (Stramski, 1999; DuRand et al., 2002).

Measurements of the particulate beam attenuation coefficient at $660 \mathrm{~nm}, c_{p}(660)$, and POC constitute the largest amount of field data presently available for examining relationships between POC and ocean optical properties. Early reports on the relationship between POC and $c_{p}(660)$ based on data from the North Atlantic and Southern Ocean (Gardner et al., 1993; Villafane et al., 1993) were soon followed by similar studies in different regions of the world's ocean (Marra, 1995; Gundersen et al., 1998; Loisel and Morel, 1998; Bishop, 1999; Claustre et al., 1999; Gardner et al., 2000; Stramska and Stramski, 2005). Most recently, Gardner et al. (2006) made a synthesis of the POC vs. $c_{p}(660)$ relationships for nine different regions comprising a total of 

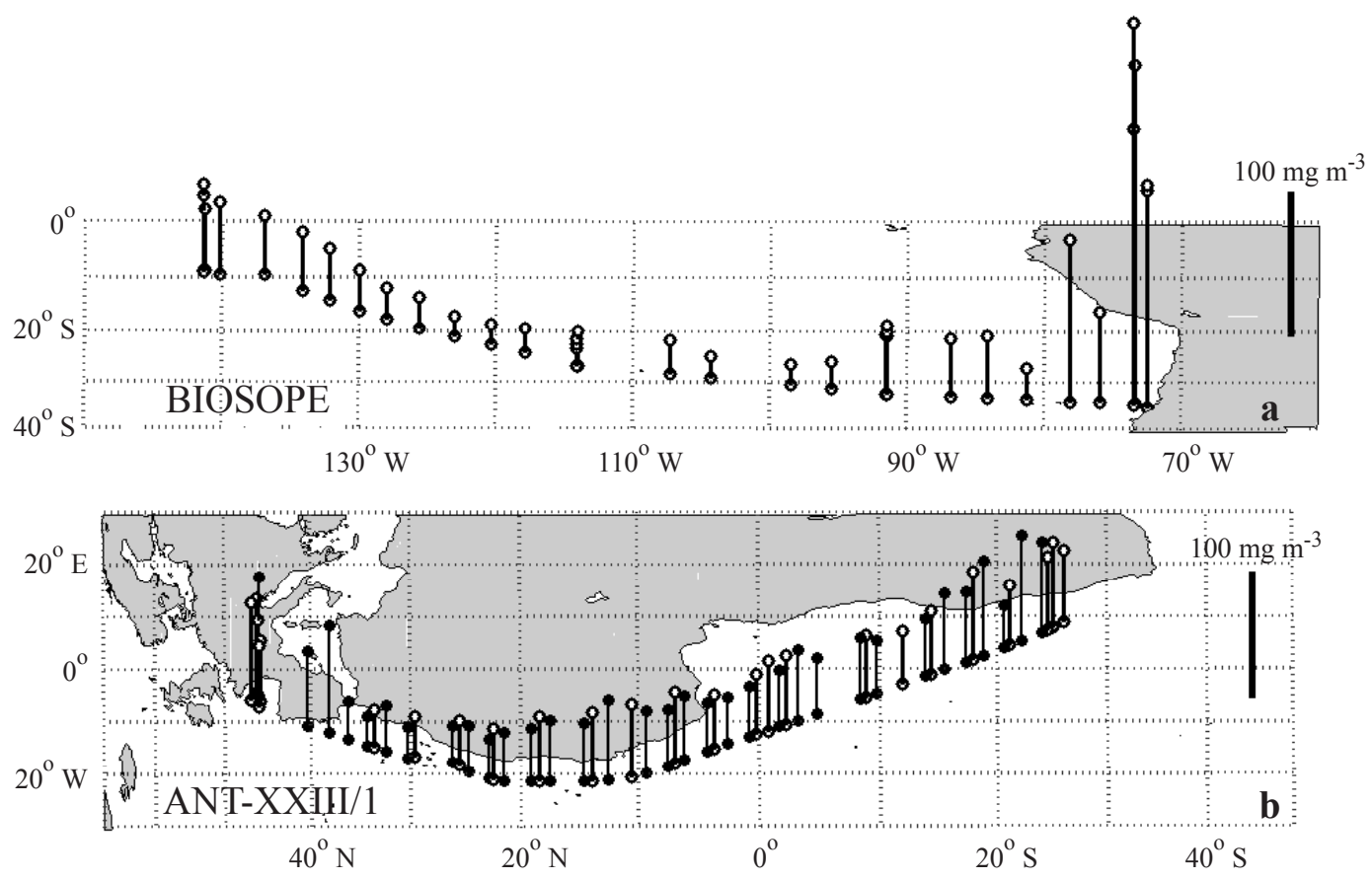

Fig. 1. Locations of stations along (a) the west-to-east BIOSOPE cruise track in the eastern South Pacific and (b) the north-to-south ANTXXIII/1 cruise track in the eastern Atlantic. The values of surface concentration of POC are illustrated with vertical bars. Lower open circles on the bars indicate locations of stations at which POC determinations were accompanied with in situ optical measurements (all stations in the case of the BIOSOPE cruise). For the ANT-XXIII/1 cruise, we additionally show a significant number of underway sampling stations at which no in situ optical measurements were taken (denoted by filled circles). The POC data from these underway stations are not included in the correlational analysis presented in this study. The scale bars at the right of each figure correspond to a POC concentration of $100 \mathrm{mg} \mathrm{m}^{-3}$.

nearly 4500 data pairs. While indicating that a linear function provides a reasonably good fit to the data, their analysis also revealed a considerable variation in the slope of the relationship ( $\sim 2$-fold) and in the squared correlation coefficient (from $\sim 0.5$ to 0.9 ) among the regional data sets.

Development of a remote sensing capability for estimating POC has led to an increased interest in the relationships between POC and the spectral remote-sensing reflectance, $R_{r s}(\lambda)$. Few studies exist in which simultaneously collected in situ data were used for the development of empirical algorithms for estimating POC directly from $R_{r s}$ or from a combination of $R_{r S}$ and IOP data (Stramski et al., 1999; Stramska and Stramski, 2005; Pabi and Arrigo, 2006). Alternative approaches for remote sensing of POC have also been attempted but the algorithms were parameterized from field measurements of POC and optical data that were not all collected in situ (because satellite data products were included), or were not collected during the same field experiments (Loisel et al., 2001; Loisel et al., 2002; Mishonov et al., 2003; Gardner et al., 2006). These approaches thus have significant limitations that are related primarily to mismatches between the temporal and/or spatial scales for the determinations of variables involved in the algorithms.
In this study, we collected contemporaneous POC and optical data, including the spectral remote-sensing reflectance, backscattering coefficient, and beam attenuation coefficient, along a west-to-east transect in the eastern South Pacific Ocean and along a north-to-south transect in the eastern Atlantic Ocean. We examine empirical relationships between the surface POC concentration and optical properties with emphasis on algorithms for estimating POC from remotesensing reflectance. Our primary objective is to provide candidate POC algorithms for the application of satellite ocean color imagery within the subtropical and tropical provinces of the Pacific and Atlantic Oceans.

\section{Data and methods}

\subsection{Study areas}

Field measurements in the eastern South Pacific Ocean were conducted during the French expedition BIOSOPE (BIogeochemistry \& Optics SOuth Pacific Experiment) on R/V l'Atalante, which took place from 17 October through 15 December, 2004. Measurements were taken on a west-toeast transect between the Marquesas Islands and the coast of Chile. Figure 1a shows the locations of stations at which 
data for this study were collected, and illustrates the surface concentration of POC at each station. This study area spans different ecological provinces and trophic conditions, including mesotrophic subequatorial waters near the Marquesas Islands, oligotrophic and hyperoligotrophic waters within the South Pacific Subtropical Gyre (SPSG) Province, as well as highly productive upwelling waters off Chile which comprise part of the Humboldt Current Coastal Province (Longhurst, 1998). The upwelling data were collected at both off-shelf and shelf stations. The general oceanographic conditions and variability in the bio-optical and biogeochemical characteristics for the BIOSOPE study area are summarized in Claustre et al. (2008), and the optical properties of the extremely clear waters within the SPSG are discussed in Morel et al. (2007) and Twardowski et al. (2007).

Data in the Atlantic Ocean were collected during the German expedition ANT-XXIII/1 on R/V Polarstern, which covered the period from 13 October to 17 November, 2005. Measurements were taken along a north-to-south transect in the eastern Atlantic between the Bay of Biscay and the African coast of Namibia (Fig. 1b). The stations were situated within open ocean waters that cover various ecological provinces such as North Atlantic Subtropical Gyre, North Atlantic Tropical Gyre, Eastern Tropical Atlantic, and South Atlantic Gyral Province (Longhurst, 1998). Note that the range in surface POC observed within the Atlantic study area is not as large as that encountered on the BIOSOPE cruise (Fig. 1).

As our present interest lies in determining relationships for satellite remote sensing applications, we restrict our data set to measurements obtained in the surface waters. The three main optical properties that are used in this study for correlating with POC are the remote-sensing reflectance, the beam attenuation coefficient, and the backscattering coefficient.

\subsection{POC determinations}

The POC data were obtained using a method generally consistent with JGOFS protocols (Knap et al., 1996). Surface water samples were collected from Niskin bottles triggered at a depth of $\sim 5 \mathrm{~m}$ during the CTD/rosette cast, then filtered through precombusted $25 \mathrm{~mm}$ Whatman $\mathrm{GF} / \mathrm{F}$ filters $\left(450^{\circ} \mathrm{C}\right.$ for $5 \mathrm{~h}$ ) under low vacuum (pressure differential across the filters $<150 \mathrm{~mm} \mathrm{Hg}$ ). Filtered volumes were adjusted according to expected POC concentration $(\sim 1$ to $8.4 \mathrm{~L}$ on BIOSOPE with the largest volumes in the gyre and smallest volumes in the Chilean upwelling, and $2-4 \mathrm{~L}$ on ANTXXIII/1). Following filtration, filters were transferred to clean glass scintillation vials, dried at $55^{\circ} \mathrm{C}$, and stored until post cruise analysis. A number of unused filters from each lot of precombusted filters were selected as blanks during the cruises. The blank filters were used to quantify background amount of organic carbon on filters and were processed identically to regular sample filters with the exception that the filtration step was not applied.
The determination of POC was made with a standard CHN analysis involving high temperature combustion of sample filters (Parsons et al., 1984). A CEC 440HA Elemental Analyzer (Control Equipment Corp., now Exeter Analytical) was used. Prior to combustion, $0.25 \mathrm{~mL}$ of $10 \% \mathrm{HCl}$ was applied to each filter for removal of inorganic carbon and the acid-treated filters were re-dried at $55^{\circ} \mathrm{C}$. The final values of POC concentration were calculated by subtracting the average mass of organic carbon determined on blank filters from the mass of carbon determined on sample filters, and then dividing this result by the measured volume of filtered sample. Triplicate (nearly all BIOSOPE stations) or duplicate (few BIOSOPE and all ANT-XXIII/1 stations) POC samples were taken for each station and averaged to produce the final result of POC concentration. The average coefficient of variation for replicate samples was $6 \%$ for BIOSOPE and $5 \%$ for ANT-XXIII/1.

POC determinations are subject to several potential sources of errors and there is continued need for further research to improve the methodology. Recently, Gardner et al. (2003) reviewed these issues. In brief summary, the causes for potential positive bias (overestimation) of POC include adsorption of dissolved organic carbon (DOC) onto filters during filtration and contamination of samples due to, for example, exposure to air during handling. There are, however, other causes which can produce a negative bias (underestimation) of POC, such as undersampling of the rare large particles, incomplete retention of particles on filters, and the loss of POC due to the impact of pressure differential on particles across the filters (e.g., breakage of fragile plankton cells). The quantification of all these effects is impossible from a practical standpoint, and therefore the accuracy of POC determinations remains unspecified.

Although we attempted to minimize some of these problems as much as possible in our study (e.g., minimal sample exposure to air during handling and low vacuum during filtration), other potential problems could not be directly addressed. It was previously recommended that determining proper blanks accounting for DOC adsorption is important, especially in waters with low POC (Menzel, 1966; Moran et al., 1999; Gardner et al., 2003). The methods that were used to estimate DOC adsorption involved either exposure of blank filters to filtered seawater or filtration of several different volumes of sample, plotting organic carbon mass on a filter as a function of volume filtered, and accepting the intercept on the carbon axis as a blank. We have not tested these methods in our study primarily because such special effort towards minimizing just one source of positive bias in POC determinations does not guarantee better estimates of POC, as the sources of negative bias cannot be eliminated from the applied method (e.g., incomplete retention of particles on GF/F filters). Our approach was focused on minimizing statistical uncertainties in POC estimates through the preparation of replicate samples with sufficient filtration volumes to maximize the ratio of the mass of organic carbon 
on the sample filter to that on the blank filter. This approach appeared to be especially important in hyperoligotrophic waters with surface POC below $20 \mathrm{mg} \mathrm{m}^{-3}$, where volumes exceeding $8 \mathrm{~L}$ for each replicate sample were filtered. In addition, our blank determinations are based on a relatively large number of blank filters ( $\sim 20$ per cruise). For the BIOSOPE cruise, our average blank determinations were $16.7 \mu \mathrm{g} C$ per filter for the stations west of Easter Island and $37.6 \mu \mathrm{g} \mathrm{C}$ per filter for the stations east of Easter Island (as two different lots of filters were used on the cruise). The ratio of the blank values to the mass of organic carbon on sample filters was, on average, $14 \%$ (3.7-48\% range with generally higher percentages at gyre stations). For the ANT-XXIII/1 cruise this ratio was lower, on average $4.5 \%$ and never more than $8 \%$, as the blank values were also lower (typically less than $10 \mu \mathrm{g} \mathrm{C}$ per filter). The methodological issues discussed above underscore the difficulty in accurate determinations of POC, especially at very low concentrations. Although the accuracy of POC is unknown and is likely variable, one can expect that samples differing from one another by less than about $5 \mathrm{mg} \mathrm{m}^{-3}$ cannot be resolved within current measurement uncertainties, which has particular ramifications for hyperoligotrophic waters where POC is less than $20 \mathrm{mg} \mathrm{m}^{-3}$.

\subsection{Optical measurements and data processing}

\subsubsection{Radiometric measurements and remote-sensing re- flectance}

The spectral remote-sensing reflectance, $R_{r s}(\lambda)$ in $\mathrm{sr}^{-1}$, is defined as the ratio of nadir water-leaving radiance, $L_{w}(\lambda)$, to the downwelling plane irradiance, $E_{d}(\lambda)$, where both quantities are measured just above the sea surface $\left(z=0^{+}\right)$. On the BIOSOPE cruise, $R_{r s}(\lambda)$ was determined from direct shipboard above-water measurements of $E_{d}\left(\lambda, z=0^{+}\right)$ in $\mathrm{W} \mathrm{m}^{-2} \mathrm{~nm}^{-1}$, and subsurface measurements of nadir upwelling radiance, $L_{u}(\lambda, z=0.2 \mathrm{~m})$ in $\mathrm{W} \mathrm{m}^{-2} \mathrm{~nm}^{-1} \mathrm{sr}^{-1}$, made at a depth $z$ of $0.2 \mathrm{~m}$ below the ocean surface. The underwater measurements were made with a calibrated hyperspectral profiling radiometer (HyperPro, Satlantic, Inc.) adapted to float at the sea surface and tethered such that the instrument operated at a distance of $\sim 100 \mathrm{~m}$ from the vessel. Instrument tilt was measured directly and radiometric measurements were rejected if tilt exceeded $5^{\circ}$. Measurements were made over the spectral region $380-800 \mathrm{~nm}$ with a spectral resolution of $3.3 \mathrm{~nm}$ and with each band having a full-width-half-maximum (FWHM) bandpass of $10 \mathrm{~nm}$. Dark current values were taken every 5 samples by use of an internal shutter and linearly interpolated as a function of time for each light value, and subtracted from the observations. Calibration coefficients and corrections for immersion effects were obtained following standard protocols (Mueller et al., 2003) and applied to the measurements. Irradiance and radiance data were taken for 3 minutes at each deployment, with each observation within the deployment time series rep- resenting integration times of 0.03 to $0.5 \mathrm{~s}$, depending on the intensity of the incident (ir)radiance. These measurements were then interpolated to a common time frame at an interval of $2 \mathrm{~s}$ and to a common spectral resolution every $2 \mathrm{~nm}$.

Upwelling radiance measurements taken at a depth of $0.2 \mathrm{~m}$ were propagated to the sea surface using an iterative approach that estimates the spectral diffuse attenuation coefficient from spectral ratios of measured radiance. From the computed upwelling radiance just below the surface, $L_{u}\left(\lambda, z=0^{-}\right)$, the nadir water-leaving radiance above the sea surface, $L_{w}(\lambda)$, was then determined based on the transmittance coefficient for nadir radiance across the water-air interface (Mueller et al., 2003). This transmittance coefficient includes the effects of Fresnel reflectance and a change in solid angle, so $L_{w}(\lambda) / L_{u}\left(\lambda, z=0^{-}\right)=\left[1-\left(1-n_{w}\right)^{2} /\left(1+n_{w}\right)^{2}\right] n_{w}^{-2}$, where $n_{w}$ is the refractive index of water. The values of $n_{w}$ in the visible spectral region can vary slightly near 1.34 (e.g., Mobley, 1994), so the values of $L_{w}(\lambda) / L_{u}\left(\lambda, z=0^{-}\right.$) assumed in the literature vary slightly as well. For the BIOSOPE data, $L_{w}(\lambda) / L_{u}\left(\lambda, z=0^{-}\right)=0.54$ was used. Finally, a three-minute time series of $R_{r s}$ was made by dividing the computed water-leaving radiance by the measured downward irradiance for each time interval, and an average value of $R_{r s}(\lambda)$ was computed for each deployment.

On the ANT-XXIII/1 cruise, $R_{r s}(\lambda)$ was determined from measurements of underwater vertical profiles of $L_{u}(\lambda, z)$ and $E_{d}(\lambda, z)$ with a freefall spectroradiometer, SeaWiFS Profiling Multichannel Radiometer (SPMR, Satlantic, Inc.), following standard protocols (Mueller et al., 2003). Measurements were made at 13 spectral wavebands (centered at 339 , $380,412,442,470,490,510,532,555,590,620,666$, and $682 \mathrm{~nm}$ with a FWHM bandwidth of $10 \mathrm{~nm}$ each) away from ship perturbations. Three to four replicate vertical casts were taken at each station. Initial data processing was done using ProSoft ver. 7.7 (Satlantic, Inc.), which included the application of dark offsets and manufacturer's radiometric calibration, binning data to $0.1 \mathrm{~m}$ depth interval, and rejecting data with tilt $>5^{\circ}$ (typically near the surface within the first $5 \mathrm{~m}$ ). Profiles with questionable data quality, such as profiles that did not agree with other replicate casts or profiles during variable sky conditions (for example, a heterogeneous cloud over the Sun's disk) were rejected from subsequent analysis.

For each profile accepted, a depth interval within the upper mixed layer (typically 5 to 15 or $20 \mathrm{~m}$, but variable on a cast-by-cast basis depending upon visual inspection of profiles) was defined for calculation of the vertical attenuation coefficients for downwelling irradiance $\left(K_{d}\right)$ and upwelling radiance $\left(K_{L u}\right)$. Using these $K_{d}$ and $K_{L u}$ values, the profiles of $E_{d}(\lambda, z)$ and $L_{u}(\lambda, z)$ were extrapolated from $\sim 5 \mathrm{~m}$ to immediately beneath the sea surface. The subsurface estimates of $E_{d}\left(\lambda, z=0^{-}\right)$ and $L_{u}\left(\lambda, z=0^{-}\right)$were propagated through the surface to yield the above-water estimates of downwelling irradiance, $E_{d}\left(\lambda, z=0^{+}\right)$, and water-leaving radiance, $L_{w}(\lambda)$, which 
are required for the final calculation of $R_{r s}(\lambda)$. The coefficients for propagating $E_{d}$ and $L_{u}$ through the water-air interface were: $E_{d}\left(\lambda, z=0^{+}\right) / E_{d}\left(\lambda, z=0^{-}\right)=1 / 0.957$ and $L_{w}(\lambda) / L_{u}\left(\lambda, z=0^{-}\right)=0.5425$. The value of 0.5425 is nearly the same ( $\sim 0.5 \%$ difference) as that used for the BIOSOPE data processing. Note that with our assumptions for the transmittance of irradiance and radiance, the relationship between $R_{r s}(\lambda)$ and its counterpart reflectance just below the surface is: $R_{r s}(\lambda)=0.519 L_{u}\left(\lambda, z=0^{-}\right) / E_{d}\left(\lambda, z=0^{-}\right)$. The final estimate of $R_{r s}(\lambda)$ for each ANT-XXIII/1 station was obtained by averaging the results from replicate casts.

We also note that in this study of clear ocean waters with chlorophyll- $a$ typically less than $0.5 \mathrm{mg} \mathrm{m}^{-3}$, no correction for instrument self-shading was deemed necessary, as the calculated effect on the upwelling radiance is less than $1-2 \%$ for the blue-green bands that are of primary interest to our POC algorithm development.

\subsubsection{Inherent optical properties}

The beam attenuation coefficient at $660 \mathrm{~nm}, c(660)$, was measured on both cruises with a C-Star transmissometer (WET Labs, Inc.) along a $25-\mathrm{cm}$ pathlength within seawater. On the BIOSOPE cruise, the transmissometer was interfaced to a CTD-rosette and the raw transmissometer voltages were acquired during down- and upcasts. On ANTXXIII/1, the transmissometer data were also acquired during the down- and upcasts but the instrument was part of a profiling package that included backscattering sensors and an additional C-Star transmissometer for measuring $c$ at $488 \mathrm{~nm}$. The beam attenuation coefficient can be considered as the sum of contributions due to particles $\left(c_{p}\right)$, colored dissolved organic matter CDOM $\left(c_{\mathrm{CDOM}}\right)$, and pure seawater $\left(c_{w}\right)$. At $660 \mathrm{~nm}, c_{\mathrm{CDOM}}$ in surface open ocean waters is so small that it can be safely ignored (Bricaud et al., 1981); this assumption is also supported by $a_{\mathrm{CDOM}}$ data from the BIOSOPE (A. Bricaud, personal communication) and ANT-XXIII/1 cruises (Röttgers and Doerffer, 2007). Thus, the measurements of $c(660)$ allow the determination of the particle beam attenuation as $c_{p}(660) \approx c(660)-c_{w}(660)$.

Processing of raw transmissometer data included quality checking of down- and uptraces, rejecting doubtful and excessively noisy data, and averaging into $1-\mathrm{m}$ depth bins. An important step of processing required for converting the raw transmissometer data to calibrated beam attenuation values was the determination of the highest raw transmittance voltages during each cruise, which correspond to the lowest beam attenuation values. This minimum attenuation is assumed in our data processing to represent the pure seawater coefficient, $c_{w}(660)$. This approach for determining $c_{w}(660)$ is preferred over the use of imperfect pure water calibrations of the instrument in the laboratory, and it can also account for variations in the cleanliness of optical windows or other instrumental drifts during the cruise (Loisel and Morel, 1998; Gardner et al., 2006). On BIOSOPE, the $c_{w}(660)$ values were determined on a cast-by-cast basis from transmissometer data at depths of $470-500 \mathrm{~m}$. On ANT-XXIII/1, routine deployments of our transmissometers were made to depths of 250-300 m, which precluded such an approach. At 5 stations, however, deep casts (2000-3000 m) were made with the ship's CTD-rosette which also included a transmissometer. The observed increase in transmissometer voltage between $300 \mathrm{~m}$ and the stable clear deep-water value at these stations was determined, and the average increase was subsequently used to calculate the appropriate reference voltage of $c_{w}(660)$ for transmissometers deployed on our instrument package. The $c_{p}(660)$ data averaged over the depth range of 4-6 $\mathrm{m}$ for BIOSOPE and 6-8 $\mathrm{m}$ for ANT-XXIII/1 were assumed to represent the surface beam attenuation values. The data from shallower depths were rejected because the signal measured near the sea surface often exhibited significant fluctuations. One possible cause of these fluctuations is the intermittent nature of bubble clouds entrained into water by breaking waves (Stramski and Tȩgowski, 2001; Terrill et al., 2001).

The spectral backscattering coefficient, $b_{b}(\lambda)$, was also measured with in situ instruments deployed in a vertical profiling mode. On both cruises, the determinations of $b_{b}(\lambda)$ were made from measurements with a Hydroscat- 6 and two a- $\beta$ eta sensors (HOBI Labs, Inc.). These instruments are equipped with light-emitting diodes (LEDs) and photodiode detectors arranged in a geometry that provides a measurement of the spectral volume scattering function, $\beta(\psi, \lambda)$, at an effective scattering angle of $\psi=140^{\circ}$ (Maffione and Dana, 1997). The Hydroscat-6 provided measurements at six wavebands (nominal wavelengths of 442, 470, 550, 589, 620, and $671 \mathrm{~nm})$ and the a- $\beta$ eta sensors at one waveband each (420 and $510 \mathrm{~nm}$ ). The $620-\mathrm{nm}$ band failed to operate correctly on the BIOSOPE cruise. The nominal wavelengths correspond to nominal center wavelengths of interference filters placed in front of the detectors. The FWHM bandwidth of filters was $10 \mathrm{~nm}$ and the filters have $\pm 2 \mathrm{~nm}$ tolerances on their nominal bandwidth and center wavelength. The LED bandwidths are substantially wider ( 20 to $30 \mathrm{~nm}$ ) than the filters and the LED peak does not necessarily match the filter peak for a given waveband. Therefore, the actual centroid wavelength does not necessarily match the nominal wavelength of the waveband. It is difficult to determine the exact spectral characteristics of the wavebands because the unique spectral data of the LEDs and filters used in individual instrument channels are not available. It is estimated, however, that the maximal difference between the actual centroid and nominal wavelengths would typically be 2 to 3 nanometers and perhaps 4 to $5 \mathrm{~nm}$ under worst-case assumptions (D. Dana, personal communication). These worst-case assumptions imply that the peak of the LED is outside the filter's $10 \mathrm{~nm}$ passband and the LED spectrum goes all the way to zero at one side of a $10 \mathrm{~nm}$ passband (which is very unlikely). A small spectral shift (up to $0.5-1 \mathrm{~nm}$ ) resulting from the fact that light that goes through the filters is not perfectly collimated was also 
taken into account in that estimation.

Backscattering data were calculated with a method described originally by Maffione and Dana (1997) with refinements presented in Boss and Pegau (2001). Initial data processing was done with HOBI Labs HydroSoft software version 2.71 utilizing manufacturer's calibrations, with subsequent processing carried out using custom-written software. The spectral backscattering coefficient was calculated from the measured $\beta\left(140^{\circ}, \lambda\right)$ using the relation: $b_{b}(\lambda)=b_{b p}(\lambda)+b_{b w}(\lambda)=2 \pi \chi\left[\beta\left(140^{\circ}, \lambda\right)-\beta_{w}\left(140^{\circ}, \lambda\right)\right]+$ $b_{b w}(\lambda)$. The coefficient $b_{b}(\lambda)$ is considered to be the sum of contributions from particle backscattering, $b_{b p}(\lambda)$, and pure seawater backscattering, $b_{b w}(\lambda)$. For each wavelength, we used a value of 1.13 for the $\chi$ parameter that is involved in the conversion of the particle volume scattering function, $\beta_{p}\left(140^{\circ}, \lambda\right)$, to $b_{b p}(\lambda)$ (Dana and Maffione, 2002). The values of $\beta_{p}\left(140^{\circ}, \lambda\right)$ were calculated as a difference between measured $\beta\left(140^{\circ}, \lambda\right)$ and the pure seawater values of $\beta_{w}\left(140^{\circ}, \lambda\right)$.

Theoretical estimates of pure water scattering available in the literature show some differences (Morel, 1974; Shifrin, 1988; Buiteveld et al., 1994). The main cause of the differences is the assumed value of the depolarization ratio $\delta$ for water molecules. For example, the estimates by Morel (1974) were obtained with $\delta=0.09$ and those of Buiteveld et al. (1994) with $\delta=0.051$. The lower values of $\delta$ result in lower estimates of scattering (e.g., Jonasz and Fournier, 2007; Twardowski et al., 2007). On the basis of the study by Farinato and Roswell (1975), Jonasz and Fournier (2007) suggested that an adequate value of $\delta$ may be as low as 0.039 . The theoretical estimates for lower values of $\delta$ were also shown to be closer to the experimental estimates of pure water scattering reported in Morel (1974). However, considering all the factors involved in the theoretical or experimental determinations, one may deduce that any particular approach or data set of pure water and pure seawater scattering available in the literature can involve uncertainties up to several percent. This level of uncertainty has particularly large impact on estimating particle backscattering from measurements of total backscattering in clear ocean waters where pure seawater contribution usually dominates the total backscattering signal. These issues are discussed in Morel (2007) and in greater detail in Twardowski et al. (2007).

In this study, we applied two sets of pure seawater scattering values, one representing the theoretical estimates from Morel (1974), and the other based on the procedure described in Buiteveld et al. (1994). The Morel (1974) values have commonly been used in the past, including the processing of backscattering measurements, and these values are also built-in the HOBI Labs Hydrosoft software as one standard option. The Morel (1974) spectral values of $\beta_{w}\left(140^{\circ}, \lambda\right)$ were calculated as $\beta_{w}\left(140^{\circ}, \lambda_{o}\right) \times\left(\lambda_{o} / \lambda\right)^{4.32}$ using $\beta_{w}\left(140^{\circ}, \lambda_{o}\right)=2.18 \times 10^{-4} \mathrm{~m}^{-1} \mathrm{sr}^{-1}$ at a reference wavelength $\lambda_{o}=525 \mathrm{~nm} . \quad \beta_{w}\left(140^{\circ}, 525\right)$ was determined from scattering at $90^{\circ}$ using the value of $\beta_{w}\left(90^{\circ}, 525\right)=1.46 \times 10^{-4} \mathrm{~m}^{-1} \mathrm{sr}^{-1}$ (from Table 4 in Morel, 1974) and the depolarization ratio $\delta=0.09$ (see Eq. (10) in Morel, 1974). We note that these determinations represent water temperature $T=20^{\circ} \mathrm{C}$ and salinity $S=35-39 \%$. In this study, the application of backscattering data to the POC algorithm development is focused on the use of surface values of $b_{b}$ and $b_{b p}$ at $555 \mathrm{~nm}$, which is a nominal wavelength of the green band on the Sea-viewing Wide Field-of-view Sensor (SeaWiFS) that provides satellite imagery of ocean color. At this wavelength, Morel's estimate of $b_{b w}$ is $9.22 \times 10^{-4} \mathrm{~m}^{-1}$.

The original formulas for pure water scattering given in Buiteveld et al. (1994) assume $\delta=0.051$ and allow the calculations as a function of water temperature at salinity $S=0$. The pure seawater scattering can then be calculated for any salinity using the multiplicative adjustment factor of $[1+0.3 S / 37]$ (Twardowski et al., 2007). We made such calculations for surface waters at each station where our backscattering measurements were taken, using measured values of $T$ and $S$ (see Buiteveld et al., 1994 and Twardowski et al., 2007 for a complete set of equations). For $\lambda=555 \mathrm{~nm}$, the resulting Buiteveld et al. values of pure seawater backscattering coefficient $b_{b w}$ are, on average, $8.748 \times 10^{-4} \mathrm{~m}^{-1}$ (standard deviation, $\mathrm{SD}=6.1 \times 10^{-6}, N=59$ ). The small variation about the average value is associated mainly with the encountered range of surface water temperature from about $13.3^{\circ} \mathrm{C}$ to $29.2^{\circ} \mathrm{C}$, and to a lesser extent with the range of salinity from about 33.9 to $37.1 \%$ o. Note that the average value of $b_{b w}(555)$ based on Buiteveld et al. (1994) procedure with the salinity adjustment is about $5 \%$ lower than the $b_{b w}(555)$ estimate from Morel (1974). The use of the Buiteveld et al. values increases our estimates of $b_{b p}(555)$ by over $20 \%$ for the clearest waters within the South Pacific Subtropical Gyre and by about $2 \%$ for the Chilean upwelling stations. For other stations with intermediate levels of particle load in water, this increase ranges generally from about $3 \%$ to $10 \%$. One of the POC algorithms analyzed in this study utilizes backscattering measurements at $555 \mathrm{~nm}$ (Sect. 3.3.2). For this algorithm, we report results based on both the Buiteveld et al. and Morel estimates of $b_{b w}$. Otherwise, the reported backscattering results are based on the use of Buiteveld et al. values of $b_{b w}$ unless specifically noted.

For each waveband, backscattering data also require a correction for attenuation of light (so-called " $\sigma$-correction"). This correction was made with the parameter $K_{b b}$ estimated from the relation $K_{b b}=a_{p}+a_{\mathrm{CDOM}}+0.4 b_{p}$ (HydroSoft software ver. 2.71) employing independent determinations of the spectral absorption coefficient by particles, $a_{p}(\lambda)$, spectral absorption coefficient by CDOM, $a_{\mathrm{CDOM}}(\lambda)$, and spectral scattering coefficient by particles, $b_{p}(\lambda)$. For BIOSOPE, these absorption and scattering estimates were obtained from measurements with ac-9 instruments (Twardowski et al., 1999; 2007). The spectral absorption measurements were corrected for the scattering error by subtracting the signal measured at $715 \mathrm{~nm}$ from the measurements at all other ac-9 wavelengths. In cases where backscattering spectral 
bands did not match those of the ac-9, ac-9 data were linearly interpolated with respect to wavelength to enable the $\sigma$-correction. For the ANT-XXIII/1 cruise, the estimates of $a_{\mathrm{CDOM}}(\lambda)$ and $a_{p}(\lambda)$ were obtained from high spectral resolution measurements on discrete water samples with a point-source integrating cavity absorption meter, PSICAM (Röttgers et al., 2005; Röttgers and Doerffer, 2007). The PSICAM absorption measurements and in situ beam attenuation measurements with C-Stars at 488 and $660 \mathrm{~nm}$ were used to obtain $b_{p}$ values. Accurate measurements of beam attenuation at as little as two wavelengths were shown to provide a good basis for determinations at other wavelengths in the visible spectral region (Boss et al., 2001). The power function fit was applied to our measurements at 488 and $660 \mathrm{~nm}$ to produce the spectral data of $c(\lambda)-c_{w}(\lambda)$, and hence $b_{p}(\lambda)=c(\lambda)-c_{w}(\lambda)-a_{p}(\lambda)-a_{\mathrm{CDOM}}(\lambda)$. The magnitude of $\sigma$-correction of backscattering for both cruises was small, generally $<0.5 \%$ (maximum of $4.5-5 \%$ for the blue wavelengths at upwelling stations off Chile).

After calculation of $\sigma$-corrected $b_{b}(\lambda, z)$, the profile data were split into down- and upcasts, inspected for quality, smoothed, and averaged into depth bins $(0.5$ or $1 \mathrm{~m})$. Because significant fluctuations in the measured signal were often observed at the shallowest depths, data in the near surface were not used in subsequent analyses. Surface values of backscattering were determined for each cruise by averaging over the same depth range as used for determining surface beam attenuation coefficient (4-6 $\mathrm{m}$ for BIOSOPE, $6-8 \mathrm{~m}$ for ANT-XXIII/1). After additional quality control, the surface data were typically calculated by averaging the down- and upcast values.

As we have not measured $b_{b}(555)$ (note that our closest measured nominal wavelength is $550 \mathrm{~nm}$ ), our final estimates of $b_{b}(555)$ were obtained from the power function fit applied to our spectral data of $b_{b}(\lambda)$. Because $b_{b}(\lambda)$ is expected to be generally a smooth monotonic function of $\lambda$, especially in the absence of intense phytoplankton blooms, the use of final backscattering values from the spectral power fit has an advantage of smoothing out potential positive and negative uncertainties that may be present in the measured data at individual spectral channels (for example, calibration uncertainties or the influence of a large particle on a single sensor channel). In the calculations of spectral fits $b_{b}$ vs. $\lambda$, we excluded data measured at $671 \mathrm{~nm}$ to avoid the potential effect of contamination of the backscattering signal within this waveband by chlorophyll $-a$ fluorescence. For $\lambda=550 \mathrm{~nm}$, the values from the power fit were higher, on average, by $\sim 3 \%$ than the measured values for the BIOSOPE data set. For ANT-XXIII/1 the agreement between these values was within $0.5 \%$.

The final backscattering results for the BIOSOPE cruise were obtained by averaging results from separate pre-cruise and post-cruise calibrations, which minimized the effect of the differences between these calibrations. These differences were fairly significant. For example, the final $b_{b}(555)$ based on averaging results from both calibrations are higher, on average, by $\sim 4 \%$ than the pre-cruise calibration-based estimates. For $b_{b p}(555)$ these differences are larger (average $\sim 10 \%$ and maximum $\sim 25 \%$ within the SPSG waters). For the ANT-XXIII/1 cruise, a post-cruise calibration was used.

\subsection{Ancillary analysis of discrete water samples}

The supplementary data on the bulk particulate properties used in this study include the dry mass concentration of suspended particulate matter, SPM, and the chlorophyll- $a$ concentration. During ANT-XXIII/1, SPM samples were obtained from Niskin bottles and the particulate matter was collected by filtration of 6 to $11 \mathrm{~L}$ of seawater on precombusted $\left(450^{\circ} \mathrm{C}\right.$ for $\left.4 \mathrm{~h}\right)$, prewashed (purified water), and pre-weighed glass-fiber filters (Whatman GF/F, diameter $47 \mathrm{~mm}$ ) using a protocol described in Van der Linde (1998). This protocol includes careful rinsing of filters with distilled water after filtration to remove salts. The particle mass determinations were made after the cruise with a microbalance (Sartorius Type BP210 D, resolution $0.01 \mathrm{mg}$ ). During BIOSOPE, a similar method was employed with the exception that $25 \mathrm{~mm}$ $\mathrm{GF} / \mathrm{F}$ filters were used and the filters were not prewashed. The lack of prewashing could have led to underestimation of SPM because of possible loss of filter fibers during filtration (as discussed in Sect. 3.1). At BIOSOPE stations triplicate samples were prepared for SPM determinations by filtering 1.5 to $8.4 \mathrm{~L}$ of seawater. The filters were frozen until later gravimetric analysis in laboratory. This analysis was made with a Metler-Toledo MT5 microbalance (resolution $0.001 \mathrm{mg}$ ). The average coefficient of variation for triplicate samples was $13 \%$.

In addition, at several BIOSOPE stations east of Easter Island replicate samples for SPM were collected from Niskin bottles, including the "dregs" (i.e., sample below spigot), by opening the bottom stopcock and passing the water through a screen with a pore size of $153 \mu \mathrm{m}$. The particulate samples were then collected on pre-weighed $0.4 \mu \mathrm{m}$ polycarbonate filters of $47 \mathrm{~mm}$ diameter (Poretics). After filtration, the Poretics filters were also rinsed with distilled water to remove salts, and frozen until gravimetric analysis in laboratory (Fisher Scientific accu-124D balance, $0.01 \mathrm{mg}$ resolution). The SPM determinations on Poretics filters represents the only analysis of discrete water samples in which the dregs were included. For other analyses, samples were drawn from the spigot. For several stations where SPM samples were collected on both GF/F filters and Poretics filters that included the dregs, no systematic differences between the two determinations were observed.

The BIOSOPE samples for phytoplankton pigments were analyzed by HPLC (High Performance Liquid Chromatography) with a modified version of the method of Van Heukelem and Thomas (2001) as described in Ras et al. (2007). From this analysis we here use the surface concentrations of total chlorophyll- $a$ (TChl- $a$ ), which represents the summed 
contributions of monovinyl chlorophyll- $a$ (MVChl- $a$ ), divinyl chlorophyll- $a$ (DVChl- $a$ ), chlorophyllide- $a$ (Chlide), and the allomeric and epimeric forms of chlorophylla. For the ANT-XXIII/1 cruise, surface concentration of chlorophyll- $a$ was measured with both HPLC (Van Heukelem and Thomas, 2001) and fluorometric methods (Holm-Hansen et al., 1965; Trees et al., 2002) in the Center for Hydro-Optics \& Remote Sensing (CHORS) laboratory at San Diego State University. Later analysis revealed that the CHORS HPLC system resulted in an overestimation of TChl- $a$ (C. Trees, personal communication). To obtain the corrected estimate of TChl- $a$ we applied the following equations to the original (uncorrected) estimates of major components of TChl- $a$ : MVChl- $a$ (corrected $)=0.598$ MVChl $-a$ (uncorrected $)+0.0073$ and DVChl- $a$ (corrected $)=$ 0.655 DVChl- $a$ (uncorrected) +0.0003 . The corrections for MVChl- $a$ and DVChl- $a$ were developed with field data used in the SeaHARRE-3 intercalibration experiment (C. Trees, personal communication). The surface data from ANTXXIII/1 show the relationship between the corrected HPLCderived TChl- $a$ and the fluorometric Chl- $a$ : TChl- $a=0.6738$ Chl- $a$ (fluorometric) +0.00633 (determination coefficient $R^{2}=0.981,59$ data pairs for surface samples). Such difference between the HPLC and fluorometric determinations is within the range of previous observations (Bianchi et al., 1995; Reynolds et al., 2001). In this study we present the HPLC-derived TChl- $a$ data.

\subsection{Temporal correspondence of various measurements}

On the ANT-XXIII/1 cruise, the deployments of SPMR, IOP instrument package, and CTD-rosette for water sampling usually took less than $1 \mathrm{~h}$. The SPMR and CTD-rosette were usually deployed simultaneously and the IOPs were measured either just before or after the CTD-rosette. Throughout the cruise these deployments were made between noon and 2 p.m. local time. Time differences between the acquisition of relevant data on the BIOSOPE cruise are larger than on ANT-XXIII/1 because of specific logistics and research program of BIOSOPE. During BIOSOPE the reflectance measurements with HyperPro instrument were taken, on average, at about 12:30 p.m. local time ( $\mathrm{SD}=1.5 \mathrm{~h})$, the backscattering measurements at 1:40 p.m. ( $\mathrm{SD}=2 \mathrm{~h} 15 \mathrm{~min}$ ), and the CTDrosette casts (sampling for surface POC and measurements of beam attenuation) at $2: 10 \mathrm{p} . \mathrm{m}$. ( $\mathrm{SD}=2 \mathrm{~h} 15 \mathrm{~min})$. While recognizing the practical limitations for making perfectly concurrent and co-located measurements of various variables on oceanographic cruises, we assume that our data were collected simultaneously or nearly-simultaneously for the purposes of our correlational analysis. All data were collected at relatively high solar elevation but sky conditions covered a broad range from overcast to clear skies.

\section{Results and discussion}

\subsection{Bulk characteristics of particle assemblages}

Figure 2 shows the range of variability for several bulk properties of suspended particulate matter in surface waters along the cruise tracks in the Pacific and Atlantic Oceans. For most parameters the overall range of variability in our data set is determined by the BIOSOPE data. For example, we observed over 20-fold range in POC from about 12 to $270 \mathrm{mg} \mathrm{m}^{-3}$ and nearly 100 -fold range in TChl- $a$ from 0.016 to $1.5 \mathrm{mg} \mathrm{m}^{-3}$. The lowest values were measured within the South Pacific Subtropical Gyre (SPSG) and the highest values in the upwelling area off Chile. The POC:TChl- $a$ ratio ranged from about 100 at the upwelling stations to over 1000 at the SPSG stations. The Atlantic data fall within the range of BIOSOPE data. During ANT-XXIII/1, POC ranged from 24 to $95 \mathrm{mg} \mathrm{m}^{-3}$, TChl- $a$ from 0.09 to $0.5 \mathrm{mg} \mathrm{m}^{-3}$, and POC:TChl- $a$ from 150 to 600.

The characteristic longitudinal variability observed in the BIOSOPE data may be partially attributed to relatively smooth variations in environmental forcing factors such as nutrients, temperature, and mixed layer light levels. These variations result in the trends in plankton biomass indicators (TChl- $a$, POC) and most likely also in phytoplankton physiological responses such as changes in cellular carbon to chlorophyll- $a$ ratio. In addition to possible physiological changes in phytoplankton, part of the observed variability in the POC:TChl- $a$ ratio can also be attributed to considerable variation in the detailed composition of particulate assemblages, which normally occurs at significant spatial scales across oceanic basins. This variation in particulate assemblages manifests itself, for example, through changes in the species composition of the plankton community, changes in the contributions of phytoplankton and non-phytoplankton particles to total POC, or changes in particle size distribution. All of these changes were observed along the BIOSOPE cruise track (Grob et al., 2007; Ras et al., 2007; Loisel et al., 2006; Stemmann et al., 2007). The HPLC analysis of accessory pigments for the ANT-XXIII/1 cruise (data not shown here) also indicated variation in phytoplankton composition along the latitudinal transect within the eastern Atlantic. We also note that the interplay of all the factors that contribute to the variability in the POC:TChl- $a$ ratio underscores the difficulty in directly estimating POC from chlorophyll- $a$.

Our analysis of SPM data from BIOSOPE revealed a possibility of underestimation because these determinations were made on non-prewashed GF/F filters which could have lost some mass during filtration of usually large sample volumes (due to loss of filter fibers). This hypothesis appears to be supported by the regression analysis of SPM vs. POC which shows a significant negative intercept. Specifically, for the entire BIOSOPE data set of surface samples we found that the best fit obtained with a Model II regression is: $\mathrm{SPM}=2.132$ POC $-9.839\left(R^{2}=0.928, N=34\right)$. Nearly 

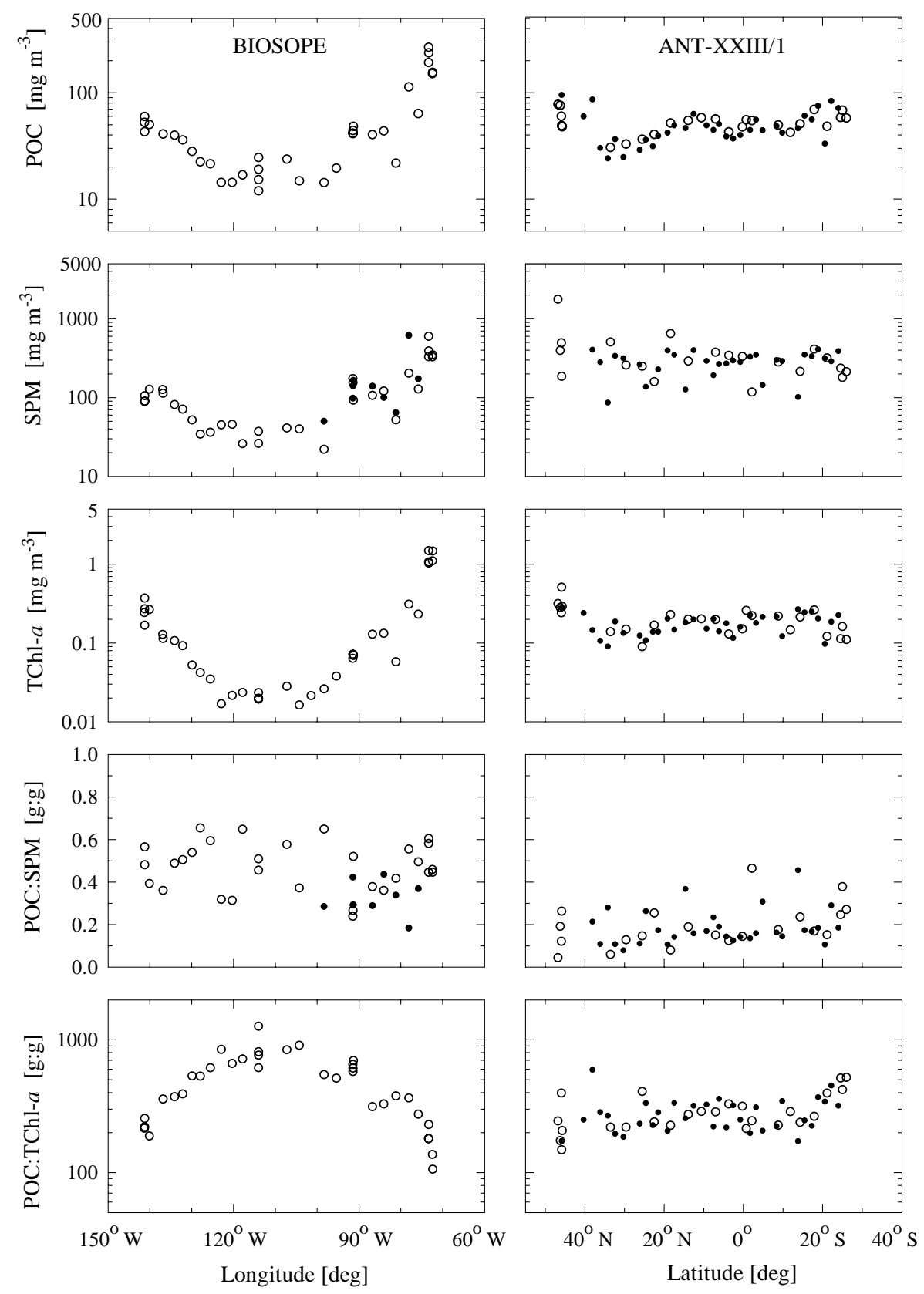

Fig. 2. Bulk characteristics of suspended particulate matter measured on surface samples along the BIOSOPE (left-hand panels) and ANTXXIII/1 (right-hand panels) cruise tracks. From top to the bottom, the graphs show the concentration of particulate organic carbon (POC), the dry mass concentration of suspended particulate matter (SPM), the total concentration of chlorophyll- $a$ derived from HPLC analysis (TChl$a$ ), the ratio of POC to SPM, and the ratio of POC to TChl- $a$. For SPM and POC:SPM data from BIOSOPE, the open circles indicate the SPM determinations on GF/F filters and the solid circles on Poretics filters. For ANT-XXIII/1 the open circles indicate data from stations where in situ optical measurements were made, and solid circles indicate data from underway stations which are not included in the correlational analysis presented in this study.

identical fit was obtained when we included additional 15 data pairs from depths between 25 and $195 \mathrm{~m}$. This analysis suggests that SPM could be underestimated, on average, at least by approximately $10 \mathrm{mg} \mathrm{m}^{-3}$. Therefore, our surface
SPM data for BIOSOPE presented in Fig. 2 were corrected by adding a value of $9.839 \mathrm{mg} \mathrm{m}^{-3}$ to the original determinations of SPM. 
Although accurate measurements of SPM in clear waters such as those within the SPSG are very difficult, we can assume that the final data of SPM and POC:SPM ratio in Fig. 2 reveal the main features of variability during the BIOSOPE cruise as well as between the BIOSOPE and ANT-XXIII/1 cruises. The range of SPM on BIOSOPE was from about 20 to $600 \mathrm{mg} \mathrm{m}^{-3}$ and that for ANT-XXIII/1 from about 100 to $650 \mathrm{mg} \mathrm{m}^{-3}$. The exception was one measurement in the Bay of Biscay with a much higher particle load $\left(\mathrm{SPM} \approx 1770 \mathrm{mg} \mathrm{m}^{-3}\right)$. It is noteworthy that the POC:SPM ratio is generally higher for BIOSOPE than ANTXXIII/1. The POC:SPM ratio varies from about 0.24 to 0.65 for BIOSOPE (based on the corrected SPM determinations on GF/F filters) and from 0.044 to 0.46 for ANT-XXIII/1. Whereas the average value for this ratio is $0.47(\mathrm{SD}=0.11)$ for the BIOSOPE cruise, it is only $0.19(\mathrm{SD}=0.09)$ for ANTXXIII/1.

The variability in POC:SPM indicates that there was variation in the composition of particulate matter in terms of relative contributions of organic and inorganic particles to SPM. Under the assumption that POC comprises 40-50\% of the total mass of particulate organic matter POM (e.g., Copin-Montégut, 1980; Honjo et al., 1995), the contribution of organic material to SPM can be roughly estimated. The relatively high values of POC:SPM data on BIOSOPE suggest the general dominance of POM in total particulate mass (from over 50\% to more than 90\%). Even if the POC:SPM ratios for BIOSOPE are still overestimated to some degree due to incomplete correction for SPM underestimation, the notion about the dominance of organic matter appears to be robust. The POC:SPM data on ANT-XXIII/1 indicate more variable scenarios. At the northernmost station located in the Bay of Biscay, the estimate of POM contribution to SPM is as low as $9-11 \%$. The ANT-XXIII/1 samples from nine other stations with locations extending southward as far as about $18^{\circ} \mathrm{N}$ suggest a relatively small role of organic matter in particulate mass concentration. The POC:SPM ratios of $0.06-0.128$ correspond to the contributions of POM to SPM of $\leq 33 \%$ at these stations. These results are consistent with observations indicating that these oceanic waters may be affected by atmospheric deposition of mineral dust transported from Africa, especially from the Sahara desert (Sarthou et al., 2003). The other extreme cases on ANT-XXIII/1 are found at a few stations south of equator which show high values of POC:SPM $(\sim 0.46)$, thus indicating that POM likely accounts for $>90 \%$ of SPM. It is also important to note that biogenic calcite particles, which include mainly coccolithophores and associated detached coccoliths (e.g., Milliman, 1993; Balch et al., 1999), could affect the above considerations in a sense that these particles contribute to SPM, but not to POM estimated from POC.

Summarizing the POC:SPM data set, we note that particulate organic matter was not always a dominant component of the total particulate matter in terms of mass. As our data include several open ocean stations in the Atlantic with the pos-
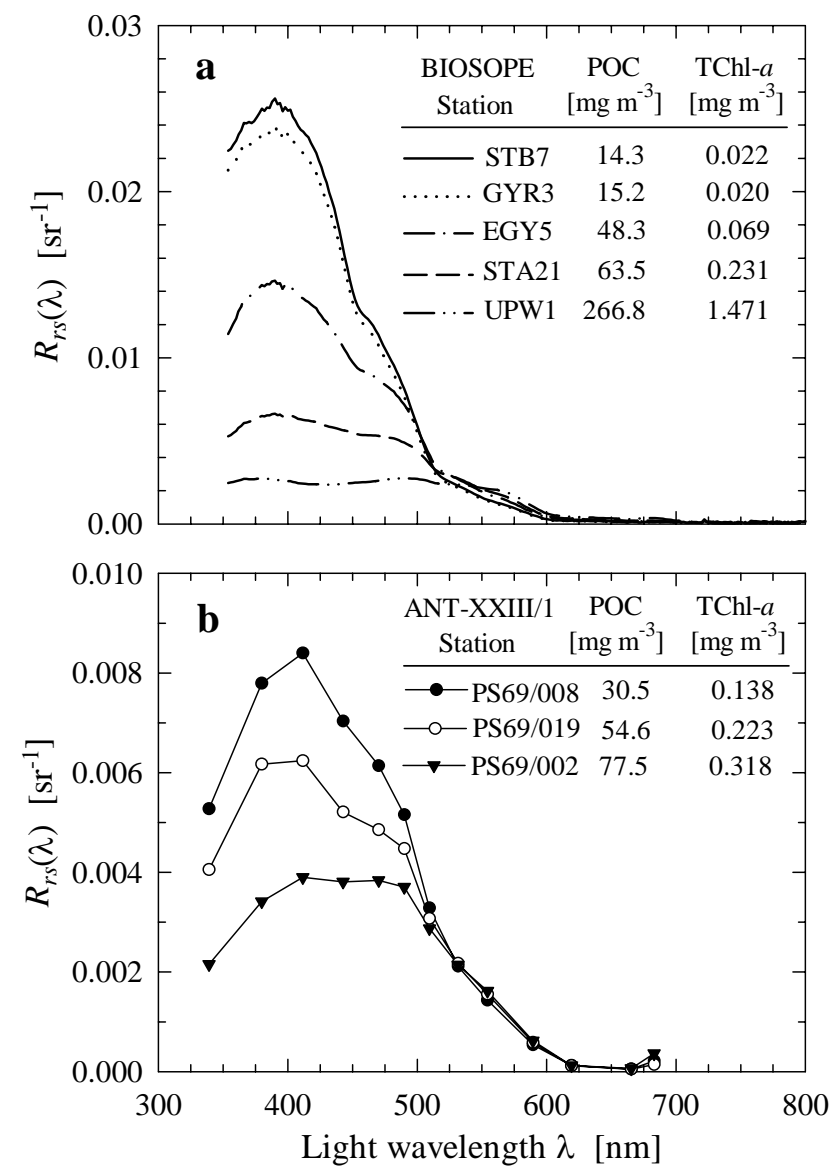

Fig. 3. Example spectra of remote-sensing reflectance, $R_{r s}(\lambda)$, measured on the BIOSOPE (a) and ANT-XXIII/1 (b) cruises at stations with different levels of surface particulate organic carbon (POC) and chlorophyll- $a$ (TChl- $a$ ) concentrations. The name of the station and the POC and TChl- $a$ concentrations are indicated.

sibility of significant contribution of non-biogenic inorganic particles to SPM, we cannot assume that all the data considered in this study satisfy the traditional bio-optical definition of the so-called Case 1 waters (Morel and Prieur, 1977; Gordon and Morel, 1983). Another point to be emphasized from the considerations presented in this section is that although our present data set for developing POC algorithms is restricted in terms of number of data points and geographic coverage, it does represent a range of variability associated with changes in both the detailed composition of particulate assemblages and the physiological status of phytoplankton communities, which occur typically in surface waters across oceanic basins.

\subsection{Reflectance band ratio algorithm for POC}

Figure 3 illustrates characteristic variations in remotesensing reflectance, $R_{r s}(\lambda)$, associated with differences in 

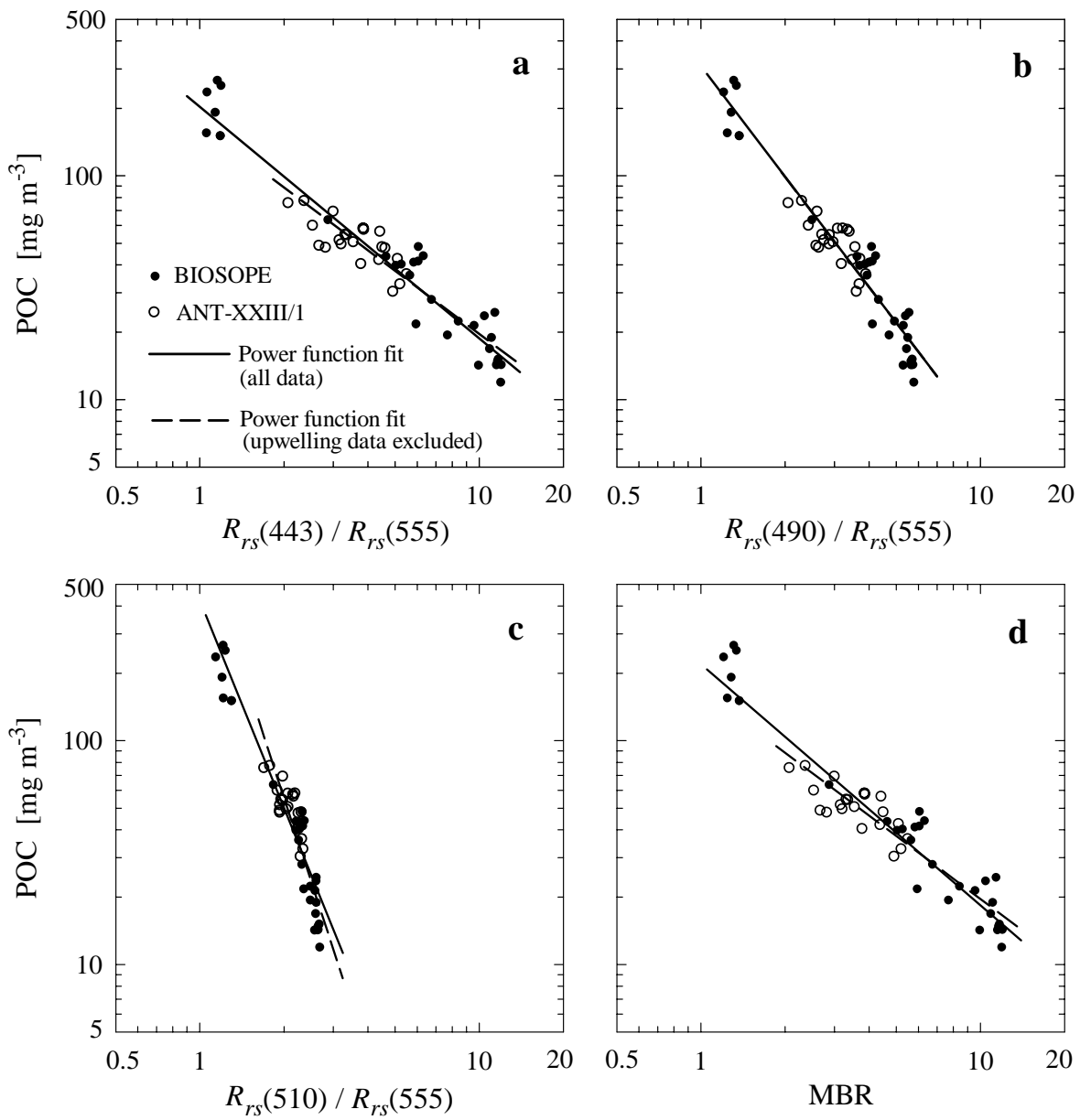

Fig. 4. Relationships between surface concentration of particulate organic carbon, POC, and the blue-to-green band ratio of remote-sensing reflectance, $R_{r s}\left(\lambda_{B}\right) / R_{r s}(555)$. The light wavelength $\lambda_{B}$ is either $443 \mathrm{~nm}$ (a), $490 \mathrm{~nm}$ (b), or $510 \mathrm{~nm}$ (c), and MBR (d) is the maximum band ratio which refers to the maximum value of the three band ratios considered. The data points for the BIOSOPE and ANT-XXIII/1 cruises and the power function fits to all data (solid lines) and the limited data sets with Chilean upwelling stations excluded (dashed lines) are shown in all panels. Note that the solid and dashed lines are indistinguishable from one another in (b) (see Table 2 for regression coefficients and error statistics).

POC and TChl- $a$ concentrations. The most pronounced variation in $R_{r s}(\lambda)$ occurs in the blue spectral region, whilst variation in the green wavebands is relatively small. For the selected BIOSOPE stations shown in Fig. 3a, we observe about 7 -fold decrease in $R_{r s}(\lambda)$ at $443 \mathrm{~nm}$ and 1.5 -fold increase at $555 \mathrm{~nm}$, which is accompanied by nearly 20 -fold increase in POC and 70-fold increase in TChl- $a$. The $R_{r s}(\lambda)$ spectra corresponding to low POC or low TChl- $a$ show higher blue-togreen (B-G) band ratios of $R_{r s}(\lambda)$ than those corresponding to higher POC and TChl- $a$. Similar observations have long been recognized as a basis for the development of empirical algorithms for estimating chlorophyll- $a$ concentration from ocean color observations (Clarke et al., 1970; O'Reilly et al., 1998). Such algorithms rely primarily on the fact that variations in $R_{r s}(\lambda)$ at blue wavelengths are driven largely by changes in the absorption coefficient of seawater due to varying concentration of pigment-containing phytoplankton and covarying biogenous matter, especially in the open ocean or Case 1 waters.

A similar reasoning can be applied to the estimation of POC from the B-G reflectance ratio by assuming that this ratio is driven largely by absorption associated with all POCcontaining particles. Although the spectral absorption properties differ among various types of organic particles such as detritus, heterotrophic organisms, and phytoplankton, it is notable that they all exhibit a common feature of increased absorption from the green toward the blue spectral region. Thus, a sizable increase in the concentration of any type of particles containing organic carbon is expected to exert a qualitatively similar effect in a sense that an increase in 
Table 1. Equations used for calculating error statistics. $P_{i}$ is the variable predicted from the regression fit, for example the predicted POC concentration (in $\mathrm{mg} \mathrm{m}^{-3}$ ), $O_{i}$ the measured variable, for example the measured POC concentration (in $\mathrm{mg} \mathrm{m}^{-3}$ ), $\bar{O}$ the mean value of measured variable, $R^{2}$ the determination coefficient, RMSE the root mean square error (in units of the measured and predicted variable), MNB the mean normalized bias (in percent), NRMS the normalized root mean square error (in percent), $N$ the number of observations, and $m$ the number of coefficients in the fit.

\begin{tabular}{ll}
\hline Determination coefficient & $R^{2}=1-\frac{\sum_{i=1}^{N}\left(P_{i}-O_{i}\right)^{2}}{\sum_{i=1}^{N}\left(O_{i}-\bar{O}\right)^{2}}$ \\
Root mean square error & $\mathrm{RMSE}=\left[\frac{1}{N-m} \sum_{i=1}^{N}\left(P_{i}-O_{i}\right)^{2}\right]^{\frac{1}{2}}$ \\
Mean normalized bias & $\mathrm{MNB}=\frac{1}{N} \sum_{i=1}^{N}\left(\frac{P_{i}-O_{i}}{O_{i}}\right) 100$ \\
Normalized root mean & $\mathrm{NRMS}=\left[\frac{1}{N-1} \sum_{i=1}^{N}\left(\frac{P_{i}-O_{i}}{O_{i}}-\frac{\mathrm{MNB}}{100}\right)^{2}\right]^{\frac{1}{2}} 100$ \\
square error &
\end{tabular}

POC will be accompanied with a decrease in the B-G reflectance band ratio. In addition to this first order effect due to concentrations of organic particles and their general absorption features in the blue-green spectral region, there will be variations in the optical properties between particle types and variations in the detailed composition of particle assemblages, which are expected to introduce some variability in the relationship between POC and the B-G ratio. Earlier tests of such empirical relationship were, however, highly encouraging (Stramska and Stramski, 2005).

Figure 4 shows the relationships between POC and the B-G band ratios of remote-sensing reflectance, $R_{r s}\left(\lambda_{B}\right) / R_{r s}(555)$, where $\lambda_{B}=443,490$, or $510 \mathrm{~nm}$, and MBR is the maximum band ratio of the three band ratios considered. Here the wavelengths of 443, 490, 510 , and $555 \mathrm{~nm}$ are used for consistency with SeaWiFS wavebands. However, these relationships may be applicable to other satellite sensors with similar bands, for example Moderate-Resolution Imaging Spectroradiometer (MODIS) bands 9,10 , and 12 that are centered approximately at 442 , 487 , and $547 \mathrm{~nm}$. The formulas used for calculating the error statistics for the various relationships examined in this study are provided in Table 1. All regression analyses presented in the figures and tables represent Model I regression, as this type of regression model is suitable for the analysis of experimental data whose aim is to provide predictive relationships between two variables (Sokal and Rohlf, 1995). The summary of regression parameters and the resulting error statistics for the relationships from Fig. 4 are given in Table 2.

A power function provides a good fit to our data of POC vs. reflectance band ratios with the determination coefficient, $R^{2}$, close to 0.9 for $R_{r s}(443) / R_{r s}(555)$, $R_{r s}(490) / R_{r s}(555)$, and MBR. The error statistics also indicate a capability for achieving relatively good estima- tion of POC from these band ratios. For example, the empirical algorithm POC vs. $R_{r s}(443) / R_{r s}(555)$ is characterized by a mean normalized bias (MNB) of $2.26 \%$ and the normalized root mean square error (NRMS) of $21.68 \%$. These errors are similar if $R_{r s}(490) / R_{r s}(555)$ or MBR are used instead of $R_{r s}(443) / R_{r s}(555)$, but noticeably higher if $R_{r s}(510) / R_{r s}(555)$ is used. The relationship POC vs. $R_{r s}(510) / R_{r s}(555)$ has the additional shortcoming of a small dynamic range of the band ratio.

We suggest that the best POC algorithms based on our data set are the power functions relating POC to $R_{r s}(443) / R_{r s}(555)$ or $R_{r s}(490) / R_{r s}(555) . \quad$ The $R_{r s}(443) / R_{r s}(555)$ data exhibit a broader dynamic range than $R_{r s}(490) / R_{r s}(555)$ and the slope of POC vs. $R_{r s}(443) / R_{r s}(555)$ is less steep than that for POC vs. $R_{r s}(490) / R_{r s}(555)$, that is -1.034 for the former relationship and -1.639 for the latter relationship. These two relationships are reasonably consistent with previous determinations based on the use of historical POC and $R_{r s}(\lambda)$ from several oceanic regions (Stramska and Stramski, 2005). For example, in that earlier study the $A$ and $B$ coefficients of the power function POC vs. $R_{r s}(443) / R_{r s}(555)$ were 196.16 and -1.114 , respectively. These values are close to 203.2 and -1.034 obtained in this study (see Table 2). Because our field data imply that the algorithms utilizing $R_{r s}(443) / R_{r s}(555)$ or $R_{r s}(490) / R_{r s}(555)$ have similar performance, we recommend that the choice of particular reflectance band ratio for the use in satellite applications should be based on the expected accuracy of the satellitederived reflectances and band ratios (see Bailey and Werdell, 2006).

The majority of POC measurements in the present data set are lower than $100 \mathrm{mg} \mathrm{m}^{-3}$, with only six higher values obtained in the Chilean upwelling waters (BIOSOPE stations UPW and UPX). We examined the influence of these stations 
Table 2. Summary of fitted equations and error statistics for the POC band ratio algorithms depicted in Fig. 4 . Power functions $\mathrm{POC}=A_{i}\left[R_{r s}\left(\lambda_{B}\right) / R_{r s}(555)\right]^{B_{i}}$ (where $R_{r s}\left(\lambda_{B}\right) / R_{r s}(555)$ is the blue-to-green band ratio of remote-sensing reflectance, $\mathrm{POC}$ is in $\mathrm{mg} \mathrm{m}^{-3}$, and $A_{i}$ and $B_{i}$ are regression coefficients) were fitted by least squares linear regression analysis using $\log _{10}$-transformed data of POC and $R_{r s}\left(\lambda_{B}\right) / R_{r s}(555)$. All regression coefficients and statistical parameters have been recalculated to represent the non-transformed data. The light wavelength $\lambda_{B}$ is either 443,490 , or $510 \mathrm{~nm}$ and MBR is the maximum band ratio which refers to the maximum value of the three band ratios considered. $R^{2}$ is the determination coefficient, RMSE the root mean square error, MNB the mean normalized bias, NRMS the normalized root mean square error, and $N$ the number of observations (see Table 1 for statistical formulas).

\begin{tabular}{cccccccc}
\multicolumn{2}{l}{$\mathrm{POC}=A_{1}\left[R_{r s}\left(\lambda_{B}\right) / R_{r s}(555)\right]^{B_{1}}$ for all data: } & & & & \\
\hline$R_{r s}\left(\lambda_{B}\right) / R_{r s}(555)$ & $A_{1}$ & $B_{1}$ & $R^{2}$ & $\begin{array}{c}\mathrm{RMSE} \\
{\left[\mathrm{mg} \mathrm{m}^{-3}\right]}\end{array}$ & $\begin{array}{c}\text { MNB } \\
{[\%]}\end{array}$ & $\begin{array}{c}\text { NRMS } \\
{[\%]}\end{array}$ & $N$ \\
\hline$R_{r s}(443) / R_{r s}(555)$ & 203.2 & -1.034 & 0.871 & 21.29 & 2.26 & 21.68 & 53 \\
$R_{r s}(490) / R_{r s}(555)$ & 308.3 & -1.639 & 0.906 & 18.38 & 2.28 & 21.71 & 52 \\
$R_{r s}(510) / R_{r s}(555)$ & 423.0 & -3.075 & 0.900 & 18.75 & 3.22 & 26.72 & 53 \\
MBR & 219.7 & -1.076 & 0.845 & 23.54 & 2.51 & 22.84 & 52 \\
\hline
\end{tabular}

$\mathrm{POC}=A_{2}\left[R_{r s}\left(\lambda_{B}\right) / R_{r s}(555)\right]^{B_{2}}$; same as above but with Chilean upwelling stations removed from the regression analysis (i.e., BIOSOPE stations UPW and UPX excluded):

\begin{tabular}{cccccccc}
\hline$R_{r S}\left(\lambda_{B}\right) / R_{r s}(555)$ & $A_{2}$ & $B_{2}$ & $R^{2}$ & $\begin{array}{c}\text { RMSE } \\
{\left[\mathrm{mg} \mathrm{m}^{-3}\right]}\end{array}$ & $\begin{array}{c}\text { MNB } \\
{[\%]}\end{array}$ & $\begin{array}{c}\text { NRMS } \\
{[\%]}\end{array}$ & $N$ \\
\hline$R_{r s}(443) / R_{r s}(555)$ & 169.7 & -0.936 & 0.804 & 7.85 & 1.96 & 20.31 & 47 \\
$R_{r s}(490) / R_{r s}(555)$ & 307.5 & -1.637 & 0.771 & 8.55 & 2.23 & 21.44 & 46 \\
$R_{r s}(510) / R_{r s}(555)$ & 792.6 & -3.828 & 0.671 & 10.17 & 2.76 & 24.06 & 47 \\
MBR & 168.6 & -0.934 & 0.807 & 7.85 & 1.97 & 20.32 & 46 \\
\hline
\end{tabular}

on the regression analysis. The regression lines obtained with upwelling stations excluded are similar to those obtained for all data (Fig. 4). For POC vs. $R_{r s}(490) / R_{r s}(555)$, the regression line without upwelling stations is actually indistinguishable from the line based on all data as the $A$ and $B$ coefficients are very similar (see Table 2 ). Whereas the $R^{2}$ values decreased, the MNB and NRMS errors improved slightly after removal of upwelling data points. In conclusion, this analysis suggests that our algorithms based on all BIOSOPE and ANT-XXIII/1 data can be, to first approximation, applicable to vast areas of subtropical and tropical Pacific and Atlantic Oceans ranging from hyperoligotrophic waters where surface POC is less than $20 \mathrm{mg} \mathrm{m}^{-3}$ to upwelling waters where POC is on the order of a few hundred milligrams per $\mathrm{m}^{3}$. Additional tests (not shown here) indicated that the power function algorithms shown in Fig. 4 and Table 2 provide better fits to our data than other formulations, such as the fourth order polynomial function currently used in the Ocean Chlorophyll (OC4) algorithm (O'Reilly et al., 2000).

It is important to note that the error statistics for the POC algorithms compare favorably with the error statistics for the band ratio chlorophyll algorithms that have been routinely used for many years (Tables 2 and 3). While the modified OC4 fit tuned to our data of TChl- $a$ vs. MBR leads to small improvements of the error statistics compared with the standard OC4, still better fit to our data is provided by a power function. The MNB and NRMS errors for this power func- tion are very similar to the errors of our best power function algorithms for POC. This result contributes additional support for the use of POC algorithms with the expectation that their performance will be similar to that of chlorophyll algorithms.

Figure 5 illustrates example results obtained with the application of our POC band ratio algorithms to the satellite imagery from SeaWiFS. Global SeaWiFS data spanning the months of January and July 2005 (900 orbits) were processed from observed top-of-atmosphere radiance to remotesensing reflectance at the native sensor resolution using the standard calibration and atmospheric correction algorithms associated with SeaWiFS Reprocessing 5.1 (Franz et al., 2005). POC was derived from the retrieved satellite $R_{r s}$ using the POC algorithms based on $R_{r s}(443) / R_{r s}(555)$ and $R_{r s}(490) / R_{r s}(555)$ (see the upper part of Table 2, all data). Satellite-derived chlorophyll- $a$ concentration $(\mathrm{Chl})$ was obtained using the OC4 version 4 chlorophyll algorithm of O'Reilly et al. (1998). After screening for clouds, cloud shadows, stray light, high sun glint, atmospheric correction failure, and algorithm failure conditions (e.g., negative $R_{r s}$ ), the derived POC and $\mathrm{Chl}$ concentrations were spatially and temporally composited into global monthly products at $9.2 \times 9.2 \mathrm{~km}$ equal area bins (Campbell et al., 1995), and then mapped to a 0.083 -deg equirectangular projection. Global images of POC obtained with the algorithm utilizing the band ratio $R_{r s}(443) / R_{r s}(555)$ are shown in Fig. 5 . These images 
are accompanied by histogram distributions that compare the number of occurrences of POC values for both the $R_{r s}(443) / R_{r s}(555)$ algorithm and the $R_{r s}(490) / R_{r s}(555)$ algorithm. The similarity of the distributions for a given month indicate that both algorithms provide similar estimates of POC. The most frequently observed values of POC range from about 30 to $60 \mathrm{mg} \mathrm{m}^{-3}$, but it is notable that the distribution for January 2005 shows a bimodal feature. The POC algorithms provide the added value to satellite observations in terms of the capability for monitoring not only the surface POC reservoir but also the POC:Chl ratio that represents a useful index of oceanic ecosystems. Figure 5 also shows the images of the POC:Chl ratio, which were determined as a ratio of the $\mathrm{POC}$ and $\mathrm{Chl}$ mapped images. The histogram distributions show that the most frequently observed values of POC:Chl are between 300 and $400 \mathrm{~g}: \mathrm{g}$, and that values below 100 or above 1000 are rare. One of the noteworthy features seen in the presented satellite images are the lowest POC and the highest POC:Chl values within the South Pacific Subtropical Gyre, which is especially well-pronounced in January 2005. These satellite-derived results for SPSG are generally consistent with our BIOSOPE measurements that were taken just a few months earlier, as shown in Fig. 2.

\subsection{Two-step algorithms for POC}

Our two-step algorithm approach consists of combining two relationships or two algorithm components, generally referred to as steps. The first step connects the apparent optical property (AOP) of the ocean with an inherent optical property (IOP) of seawater. The second step connects the seawater constituent concentration with the IOP. In the application of the two-step algorithm, the first step provides a means for estimating IOP from remote-sensing reflectance, and the second step for estimating POC from the IOP. This two-step feature may be particularly useful for developing an understanding of bio-optical variability underlying the algorithms and also offers flexibility in the development of regional or seasonal parameterizations of the algorithms. For example, while the first step can possibly be developed in such a way that it is fairly robust over large oceanic regions or generally weakly dependent on environmental conditions, the second step may require significant tuning to regional or seasonal variability within the ocean.

We examined three different versions of the two-step algorithm. In the first two versions, which can be referred to as two-step empirical approaches, both steps of the algorithm utilize empirical relationships. In the third version, referred to as two-step hybrid approach, a semianalytical model for estimating IOPs from reflectance is used in the first step of the algorithm, and then the empirical relationship is used in the second step of the algorithm.

Specifically, in the first version of our two-step empirical algorithm, the AOP is the blue-to-green reflectance band ratio, $R_{r s}\left(\lambda_{B}\right) / R_{r s}(555)$, which is linked to the particulate
Table 3. Summary of error statistics for the Ocean Chlorophyll 4 (OC4) algorithm tested with the BIOSOPE and ANT-XXIII/1 data. The OC4 algorithm estimates the surface chlorophyll- $a$ concentration as $10^{p_{1}+p_{2} X+p_{3} X^{2}+p_{4} X^{3}+p_{5} X^{4}}$, where $X=\log _{10}(\mathrm{MBR})$ and MBR is the maximum band ratio of remote-sensing reflectance. The error statistics are shown for the standard OC4v4 algorithm (where v4 stands for version 4 ) whose regression coefficients are: $p_{1}=0.366 ; p_{2}=-3.067 ; p_{3}=1.93 ; p_{4}=0.649 ;$ and $p_{5}=-1.532$ (O'Reilly et al., 2000). For comparison, included are the error statistics for a modified OC4 fit and for the power function fit obtained from the regression analysis applied to the BIOSOPE and ANT-XXIII/1 data. The modified OC4 fit was obtained by fitting the OC4 formula to the data while constraining the regression coefficients to within $50 \%$ of the standard OC4v4 coefficients. The modified OC4 coefficients are: $p_{1}=0.472 ; p_{2}=-3.549 ; p_{3}=2.843$; $p_{4}=0.3245$; and $p_{5}=-1.768$. The power function fit to our data is TChl- $a=1.8814 \mathrm{MBR}^{-1.8233} . R^{2}$ is the determination coefficient, RMSE the root mean square error, MNB the mean normalized bias, NRMS the normalized root mean square error, and $N$ the number of observations (see Table 1 for statistical formulas).

\begin{tabular}{cccccc}
\hline & $R^{2}$ & $\begin{array}{c}\text { RMSE } \\
{\left[\mathrm{mg} \mathrm{m}^{-3}\right]}\end{array}$ & $\begin{array}{c}\text { MNB } \\
{[\%]}\end{array}$ & $\begin{array}{c}\text { NRMS } \\
{[\%]}\end{array}$ & $N$ \\
\hline Standard OC4 & 0.930 & 0.094 & 2.85 & 35.78 & 51 \\
Modified OC4 & 0.912 & 0.105 & -2.64 & 28.96 & 51 \\
Power function & 0.937 & 0.089 & 2.35 & 22.60 & 51 \\
\hline
\end{tabular}

beam attenuation coefficient, $c_{p}(660)$. In the second step of the algorithm, POC is linked to $c_{p}(660)$. This approach has been previously examined with data from the north polar Atlantic and it was used to study surface POC in that region with satellite observations (Stramska and Stramski, 2005).

In the second version of our two-step empirical algorithm, the AOP and IOP quantities are both at a single waveband in the green spectral region. In the first step, the remotesensing reflectance, $R_{r s}(555)$, is linked to the backscattering coefficient, $b_{b}(555)$, and in the second step POC is linked to particulate backscattering, $b_{b p}(555)$. This type of twostep algorithm to estimate POC from ocean reflectance has been previously proposed and tested with satellite data in the Southern Ocean (Stramski et al., 1999).

Finally, in the hybrid version of our two-step algorithm, we tested two semianalytical models for estimating the backscattering coefficient, $b_{b}(555)$, from remote-sensing reflectance. The semianalytical models are thus used as a first step of the hybrid algorithm. The second step of the algorithm is simply represented by the empirical relationship between POC and $b_{b p}(555)$. We note that the hybrid approach may, in principle, be also applicable to the two-step algorithm involving the beam attenuation coefficient as an IOP. Attempts to develop reflectance inversion models for estimating particle beam attenuation have been undertaken (Roesler and Boss, 2003), but this approach is not tested in our study. 

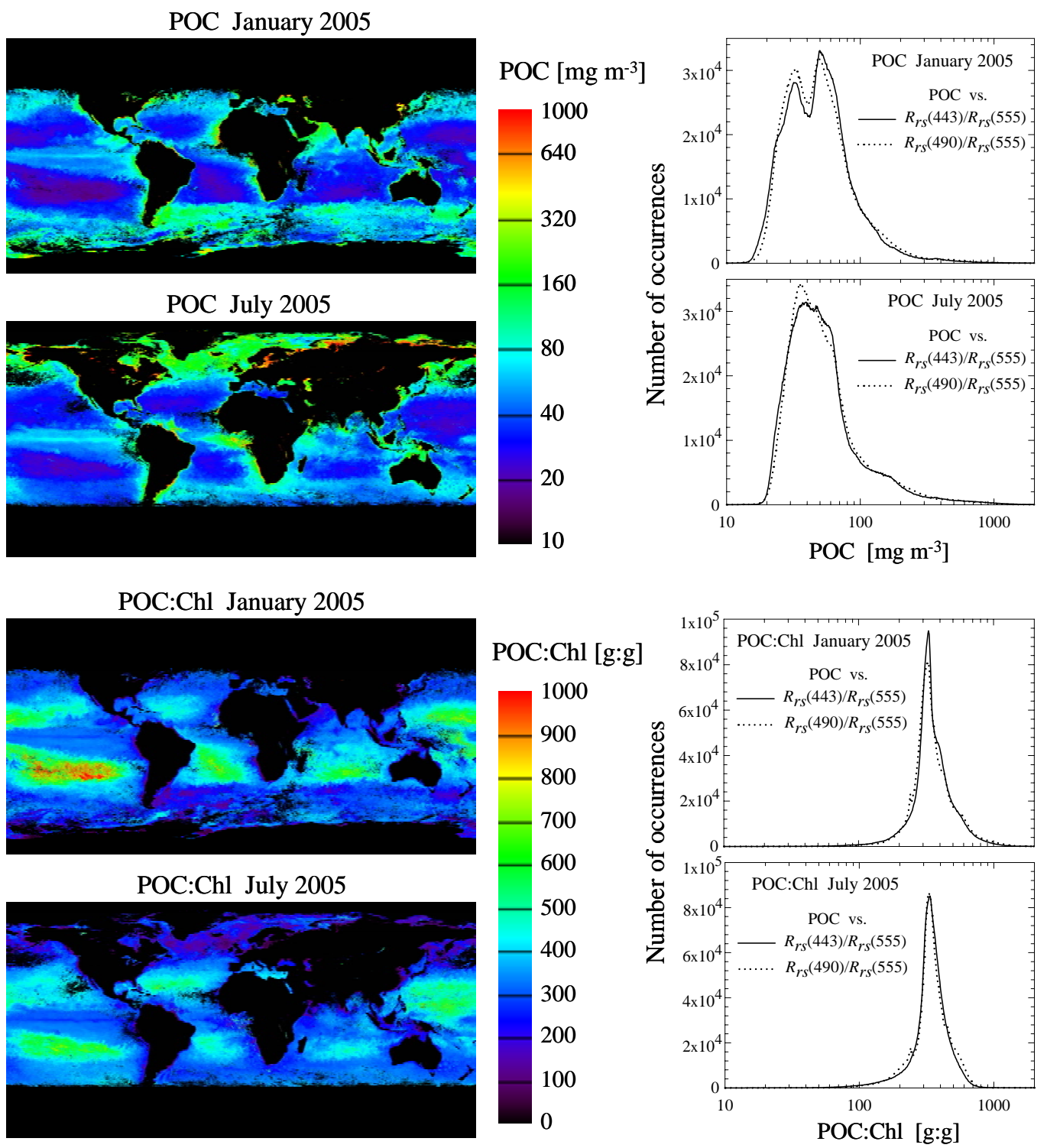

Fig. 5. Monthly composite images (left-hand panels) of surface concentration of particulate organic carbon (POC) and the POC-tochlorophyll- $a$ ratio (POC:Chl). The images were derived from satellite observations with SeaWiFS in January 2005 and July 2005 (see text for details). POC images are presented in a logarithmic scale from 10 to $1000 \mathrm{mg} \mathrm{m}^{-3}$ and the POC:Chl images are linearly scaled from 0 to 1000 (g:g). The images were derived using the POC algorithm based on $R_{\mathrm{rs}}(443) / R_{\mathrm{rs}}(555)$. The histogram distributions corresponding to each image are presented in right-hand panels. For comparison, additional histograms obtained using the POC algorithm based on $R_{\mathrm{rs}}(490) / R_{\mathrm{rs}}(555)$ are shown. All histograms were created using bins of constant width (0.005) for the log-transformed variables of POC and POC:Chl.

\subsubsection{Reflectance band ratio vs. beam attenuation approach}

Figures 6 and 7 illustrate a two-step empirical approach to the POC algorithm development, which involves $R_{r s}\left(\lambda_{B}\right) / R_{r s}(555)$ as an $\mathrm{AOP}$ and $c_{p}(660)$ as an IOP. Our data show that $c_{p}(660)$ can be estimated from $R_{r s}\left(\lambda_{B}\right) / R_{r s}(555)$ (Fig. 6). As indicated by the error statistics in Table 4 , the best results are obtained when
$R_{r s}(443) / R_{r s}(555)$ or maximum-band ratio (MBR) are used. In these cases the MNB values are below 3\% and the NRMS below $25 \%$. We point out that $c_{p}(660)$ can be reasonably well estimated from $R_{r s}\left(\lambda_{B}\right) / R_{r s}(555)$ using a single relationship derived from our entire data set covering waters from hyperoligotrophic to upwelling areas. This is noteworthy as it suggests that the relationship between $\left.c_{p}(660)\right)$ and $R_{r s}\left(\lambda_{B}\right) / R_{r s}(555)$ can represent a fairly robust component 

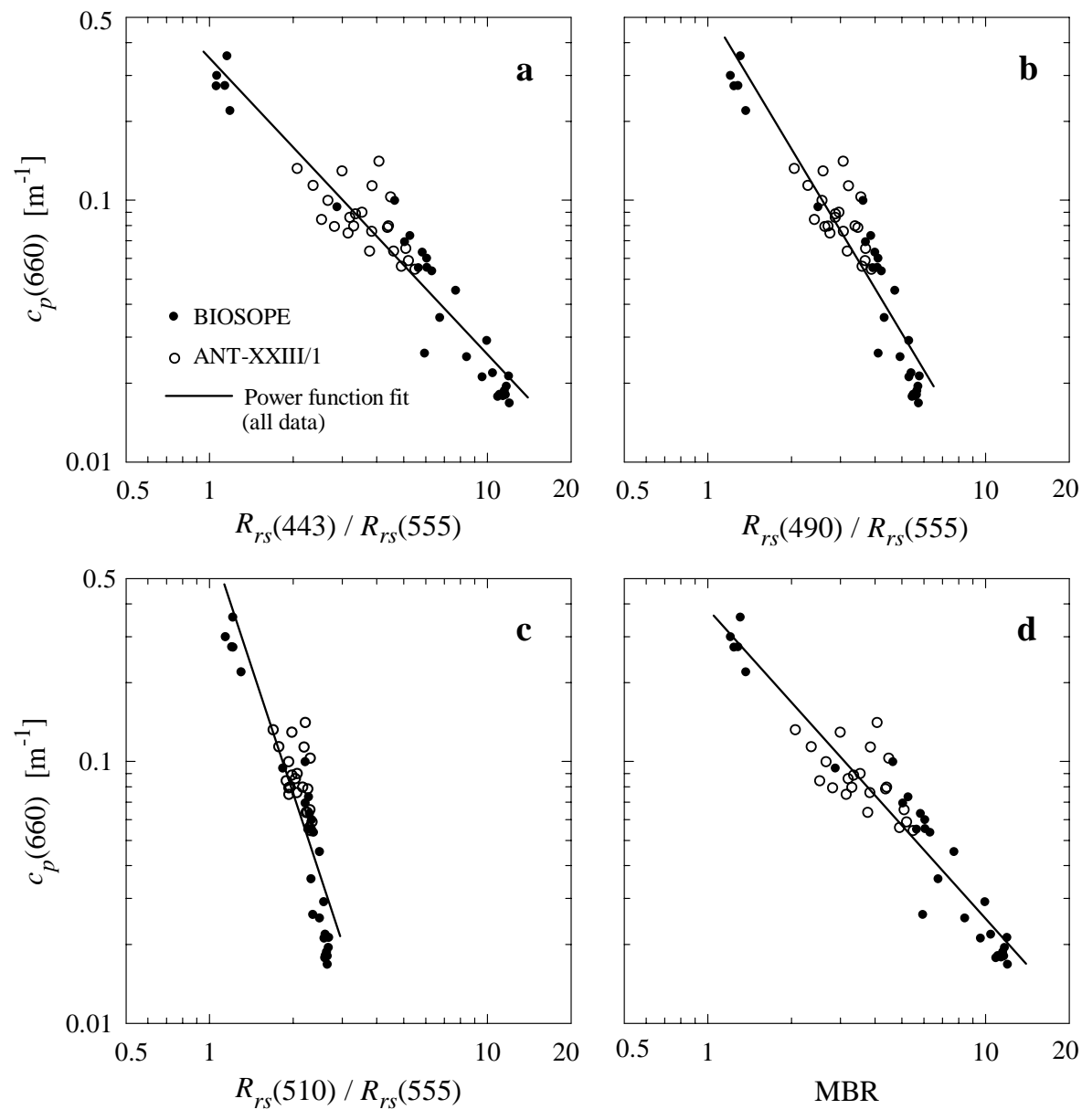

Fig. 6. Relationships between surface values of the particulate beam attenuation coefficient, $c_{p}(660)$, and the blue-to-green band ratio of remote-sensing reflectance, $R_{r s}\left(\lambda_{B}\right) / R_{r s}(555)$. The light wavelength $\lambda_{B}$ is either $443 \mathrm{~nm}(\mathbf{a}), 490 \mathrm{~nm}(\mathbf{b})$, or $510 \mathrm{~nm}(\mathbf{c})$, and MBR (d) is the maximum band ratio which refers to the maximum value of the three band ratios considered. The data points for the BIOSOPE and ANT-XXIII/1 cruises and the power function fits to all data are shown in all panels (see Table 4 for regression coefficients and error statistics).

of the two-step POC algorithm. Such robustness may appear somewhat surprising because variations in $c_{p}(660)$ are driven primarily by particle scattering in the red part of the spectrum and variations in $R_{r s}\left(\lambda_{B}\right) / R_{r s}(555)$ by particle and CDOM absorption in the blue part of the spectrum. It is apparently a high degree of covariation of these processes within our data set that explains this result. We also note that previous analysis of data from the north polar Atlantic suggested that this relationship can show little sensitivity to regional and seasonal bio-optical variability (Stramska and Stramski, 2005; Stramska et al., 2006). Both the previous and present results indicate that the $c_{p}(660)$ vs. $R_{r s}\left(\lambda_{B}\right) / R_{r s}(555)$ relationship represents a promising component of the two-step POC algorithm, which requires attention in future research.

The data for the second relationship of the two-step algorithm, POC vs. $c_{p}(660)$, show that a linear function provides a reasonably good fit to our entire data set (Fig. 7). This fit has MNB of about $-3 \%$ and NRMS of about $25 \%$ (Table 4$)$. We also examined the regression POC vs. $c_{p}(660)$ with the five upwelling data pairs excluded. This resulted in a decrease in the slope and an increase of the intercept of the linear fit. The slope of $\sim 460$ (units are $\mathrm{mg} \mathrm{C} \mathrm{m}^{-2}$ ) for our fit with no upwelling data is within the range reported for different regions of the world's oceans (Gardner et al., 2006). The slope of $\sim 660$ based on all our data including the five upwelling data pairs is similar to the steepest slope in the data set of Gardner et al. (2006), which was observed by those investigators in the Ross Sea. The relatively steep slopes $(\sim 500-585)$ were also previously observed in tropical and equatorial Pacific waters (Claustre et al., 1999; Behrenfeld and Boss, 2006; Gardner et al., 2006). On the basis of 3462 data pairs from eight regions (not including the Ross Sea), Gardner et al. (2006) determined the average slope of $\sim 380$, which is smaller than the estimates in the present study. Unlike our analysis, however, the Gardner et al. database is not 
Table 4. Summary of fitted equations and error statistics for the two-step empirical POC algorithm depicted in Figs. 6 and 7. The coefficients $C_{1}$ and $C_{2}$ of power function (i.e., step 1 equation) were obtained from least squares linear regression analysis using $\log _{10}$-transformed data of $c_{p}(660)$ and $R_{r s}\left(\lambda_{B}\right) / R_{r s}(555)$. The regression coefficients and statistical parameters have been recalculated to represent the nontransformed data. The ordinary least squares linear regression was applied to calculate the coefficients $D_{1}$ and $D_{2}$ of the step 2 equation. $c_{p}(660)$ is in $\mathrm{m}^{-1}$ and POC is in $\mathrm{mg} \mathrm{m}^{-3} . R^{2}$ is the determination coefficient, RMSE the root mean square error, MNB the mean normalized bias, NRMS the normalized root mean square error, and $N$ the number of observations (see Table 1 for statistical formulas).

\begin{tabular}{cccccccc} 
Step 1 equation: $c_{p}(660)=C_{1}\left[R_{r s}\left(\lambda_{B}\right) / R_{r s}(555)\right]^{C_{2}}$ \\
\hline$R_{r s}\left(\lambda_{B}\right) / R_{r s}(555)$ & $C_{1}$ & $C_{2}$ & $R^{2}$ & $\begin{array}{c}\text { RMSE } \\
{\left[\mathrm{m}^{-1}\right]}\end{array}$ & $\begin{array}{c}\text { MNB } \\
{[\%]}\end{array}$ & $\begin{array}{c}\text { NRMS } \\
{[\%]}\end{array}$ & $N$ \\
\hline$R_{r s}(443) / R_{r s}(555)$ & 0.349 & -1.131 & 0.896 & 0.0243 & 2.93 & 24.45 & 52 \\
$R_{r s}(490) / R_{r s}(555)$ & 0.536 & -1.771 & 0.836 & 0.0308 & 3.99 & 28.38 & 51 \\
$R_{r s}(510) / R_{r s}(555)$ & 0.704 & -3.224 & 0.702 & 0.0412 & 7.12 & 39.56 & 52 \\
MBR & 0.382 & -1.182 & 0.906 & 0.0233 & 2.91 & 24.55 & 51 \\
\hline
\end{tabular}

Step 2 equation: $\mathrm{POC}=D_{1} c_{p}(660)+D_{2}$

\begin{tabular}{cccccccc}
\hline & $D_{1}$ & $D_{2}$ & $R^{2}$ & $\begin{array}{c}\text { RMSE } \\
{\left[\mathrm{mg} \mathrm{m}^{-3}\right]}\end{array}$ & $\begin{array}{c}\text { MNB } \\
{[\%]}\end{array}$ & $\begin{array}{c}\text { NRMS } \\
{[\%]}\end{array}$ & $N$ \\
\hline All data & 661.9 & -2.168 & 0.934 & 12.95 & -2.98 & 24.98 & 59 \\
Upwelling data excluded & 458.3 & 10.713 & 0.888 & 6.68 & 4.63 & 21.29 & 54 \\
\hline
\end{tabular}

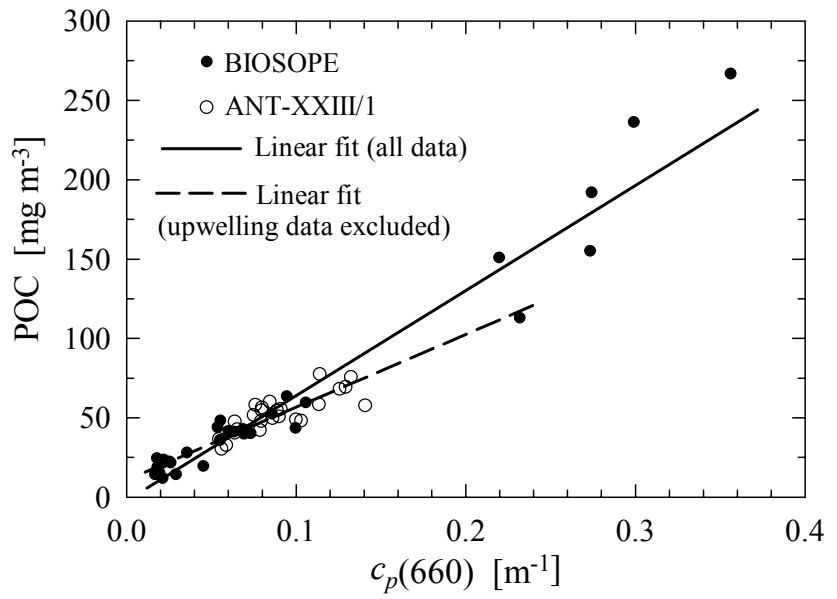

Fig. 7. Relationship between surface concentration of particulate organic carbon, POC, and particulate beam attenuation coefficient, $c_{p}(660)$. The data points for the BIOSOPE and ANT-XXIII/1 cruises and the linear function fits to all data (solid line) and the limited data sets with Chilean upwelling stations excluded (dashed line) are shown (see Table 4 for regression coefficients and error statistics).

limited to surface data but includes the upper ocean layer to a depth of about $250 \mathrm{~m}$. It is possible that the variability observed in that large data set is associated not only with regional differentiation but also partly with vertical variations (see also Loisel and Morel, 1998).
Another factor that deserves attention in such comparative analysis is the potential difference in the estimates of the measured beam attenuation coefficient obtained with various types of commercial or custom-built beam transmissometers that have different acceptance angle for the detector. This is a critical technical parameter for measuring beam attenuation. Although the effective acceptance angle should be as small as practically possible, differences exist between instrument models. Instruments with larger acceptance angles are expected to provide lower estimates of beam attenuation, i.e., larger underestimation of true beam attenuation, compared with instruments with smaller acceptance angles. Unfortunately, manufacturers often do not provide information on the effective acceptance angle in the specifications of commercial beam transmissometers.

The aggregate error statistics for the two-step algorithm depicted in Figs. 6 and 7 are reasonably good regardless of whether or not the Chilean upwelling data are included in the analysis (Table 5). The differences in carbon-specific beam attenuation coefficient, $c_{p, \text { POC }}^{*}(660)$, within our data set are generally small. For BIOSOPE the average $c_{p, \text { POC }}^{*}(660)$ is $1.46 \times 10^{-3} \mathrm{~m}^{2}(\mathrm{mgC})^{-1}\left(\mathrm{SD}=3.9 \times 10^{-4}, N=34\right)$. Nearly identical average is obtained for that cruise with five upwelling data excluded. For ANT-XXIII/1, the average $c_{p, \mathrm{POC}}^{*}(660)$ is $1.69 \times 10^{-3} \mathrm{~m}^{2}(\mathrm{mg} \mathrm{C})^{-1} \quad\left(\mathrm{SD}=2.7 \times 10^{-4}\right.$, $N=25)$. We note, however, that the potential differentiation of the POC vs. $c_{p}(660)$ relationship in surface oceanic waters could be used as a basis for developing region- or seasonspecific parameterizations of the two-step algorithm. 
Table 5. Summary of aggregate error statistics for the composite representation of the two-step empirical POC algorithm depicted in Figs. 6 and 7. The composite formulation of the algorithm is: $\mathrm{POC}=D_{1}\left\{C_{1}\left[R_{r s}\left(\lambda_{B}\right) / R_{r s}(555)\right]^{C_{2}}\right\}+D_{2}$. The coefficients $C_{1}$ and $C_{2}$ of the step 1 equation and the coefficients $D_{1}$ and $D_{2}$ of the step 2 equation are given in Table 4 . POC is in $\mathrm{mg} \mathrm{m}^{-3}, R^{2}$ is the determination coefficient, RMSE the root mean square error, MNB the mean normalized bias, NRMS the normalized root mean square error, and $N$ the number of observations (see Table 1 for statistical formulas).

\begin{tabular}{|c|c|c|c|c|c|}
\hline$R_{r S}\left(\lambda_{B}\right) / R_{r s}(555)$ & $R^{2}$ & $\begin{array}{c}\text { RMSE } \\
{\left[\mathrm{mg} \mathrm{m}^{-3}\right]}\end{array}$ & $\begin{array}{c}\text { MNB } \\
{[\%]}\end{array}$ & $\begin{array}{c}\text { NRMS } \\
{[\%]}\end{array}$ & $N$ \\
\hline$R_{r s}(443) / R_{r s}(555)$ & 0.889 & 18.07 & -5.43 & 23.28 & 52 \\
\hline$R_{r s}(490) / R_{r s}(555)$ & 0.875 & 19.31 & -5.36 & 21.84 & 51 \\
\hline$R_{r s}(510) / R_{r s}(555)$ & 0.823 & 22.79 & -4.56 & 24.84 & 52 \\
\hline MBR & 0.885 & 18.54 & -5.01 & 24.74 & 51 \\
\hline
\end{tabular}

BIOSOPE upwelling data excluded:

\begin{tabular}{cccccc}
\hline$R_{r s}\left(\lambda_{B}\right) / R_{r s}(555)$ & $R^{2}$ & $\begin{array}{c}\text { RMSE } \\
{\left[\mathrm{mg} \mathrm{m}^{-3}\right]}\end{array}$ & $\begin{array}{c}\text { MNB } \\
{[\%]}\end{array}$ & $\begin{array}{c}\text { NRMS } \\
{[\%]}\end{array}$ & $N$ \\
\hline$R_{r s}(443) / R_{r s}(555)$ & 0.793 & 8.26 & 4.25 & 25.20 & 47 \\
$R_{r s}(490) / R_{r s}(555)$ & 0.777 & 8.64 & 3.62 & 28.23 & 46 \\
$R_{r s}(510) / R_{r s}(555)$ & 0.638 & 10.91 & 3.17 & 35.73 & 47 \\
MBR & 0.794 & 8.32 & 5.46 & 24.65 & 46 \\
\hline
\end{tabular}

\subsubsection{Single-wavelength reflectance vs. backscattering ap- proach}

The relationships of the two-step empirical algorithm utilizing a single wavelength of $555 \mathrm{~nm}$ are shown in Fig. 8 . In this green spectral region absorption by most particle types is weak. Therefore, one may expect that the variation in $R_{r S}(555)$ will be often driven largely by changes in the backscattering coefficient $b_{b}(555)$, and to a lesser degree by absorption, especially in clear oceanic waters. Overall, however, as a result of interplay of absorption and backscattering we observe relatively small changes in $R_{r s}(555)$ with an increase in POC compared to changes in $R_{r s}$ at the blue wavelengths (see Fig. 3). This type of POC algorithm based on single-wavelength reflectance offers the potential benefit of decoupling the estimation of POC from the estimation of chlorophyll- $a$ that is based on the B-G band ratio of reflectance. There are, however, limitations of the singlewavelength algorithm, especially for satellite applications. Specifically, this algorithm will be highly sensitive to the accuracy of the magnitude of satellite-derived reflectance, and the required accuracy may not be easily achieved on a routine basis. This requirement is generally not as critical when reflectance band ratios are used. Also, whereas the single-wavelength two-step algorithm is characterized by a relatively small dynamic range of $R_{r s}$ in the green spectral region, the B-G band ratio algorithm is characterized by a
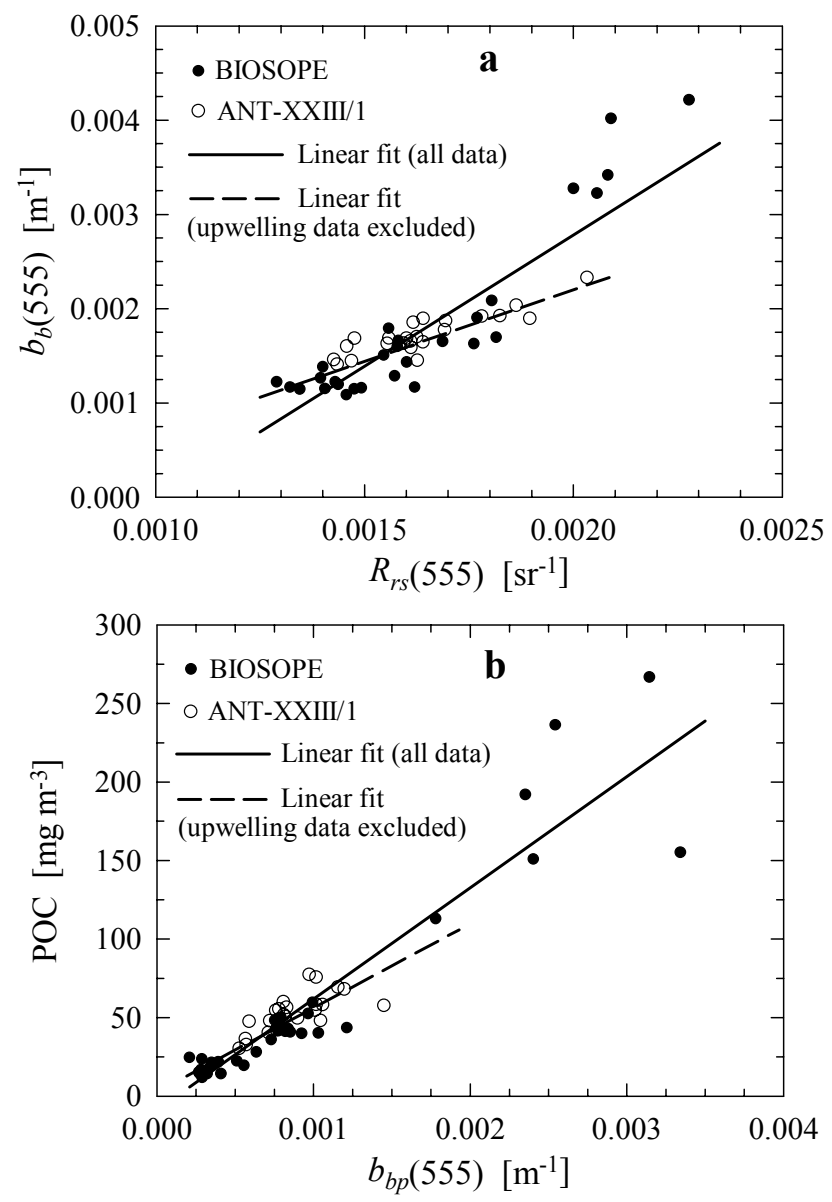

Fig. 8. (a) Relationship between surface values of the backscattering coefficient, $b_{b}(555)$, and remote-sensing reflectance, $R_{r s}(555)$. (b) Relationship between surface concentration of particulate organic carbon, POC, and particulate backscattering coefficient, $b_{b p}(555)$. The data points for the BIOSOPE and ANT-XXIII/1 cruises and the linear function fits to all data (solid lines) and the limited data sets with Chilean upwelling stations excluded (dashed lines) are shown in both panels (see Table 6 for regression coefficients and error statistics).

larger dynamic range due to large variations in $R_{r s}$ at blue wavelengths in response to variations in POC (see Fig. 3).

In the application of the single-wavelength empirical algorithm, the backscattering coefficient $b_{b}(555)$ is first determined from $R_{r s}(555)$ (Fig. 8a), and then POC is estimated from $b_{b p}(555)$, where $b_{b p}(555)=b_{b}(555)-b_{b w}(555)$ (Fig. 8b). The regression coefficients and error statistics for these relationships are presented in Table 6 , which includes results for two estimates of pure seawater backscattering coefficient, $b_{b w}$ (555), one based on Buiteveld et al. (1994) with the salinity adjustment and the other based on Morel (1974). The step 1 relationship is nearly the same for both versions of $b_{b w}(555)$, because the final estimates of $b_{b}(555)$ show very 


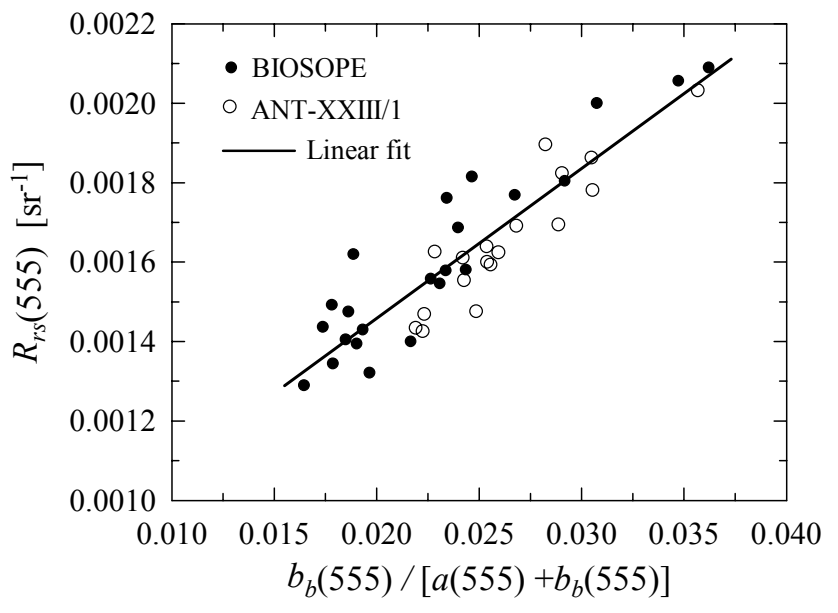

Fig. 9. Relationship between remote-sensing reflectance, $R_{r s}(555)$, and the ratio of absorption to the sum of absorption and backscattering coefficients, $b_{b}(555) /\left[a(555)+b_{b}(555)\right]$. The data points for the BIOSOPE and ANT-XXIII/1 cruises and the linear function fit to all data are shown. The equation of the fit is: $R_{r s}(555)=0.03771 b_{b}(555) /\left[a(555)+b_{b}(555)\right]+7.04 \times 10^{-4}$ (coefficient of determination $R^{2}=0.822$, number of observations $N=41$ ). At the limit of pure seawater, the results of this regression analysis within $95 \%$ confidence interval are consistent with radiative transfer simulations.

small changes due to the variation in the assumed values of $b_{b w}$ (555). The effect of $b_{b w}(555)$ on the step 2 relationship involving $b_{b p}(555)$ is noticeable, especially for the intercept coefficient, albeit still small. The aggregate error statistics calculated from the composite formula of the two-step algorithm are nearly the same for both estimates of $b_{b w}(555)$ but show relatively large errors which caution against indiscriminate use of this algorithm (Table 6). The separate relationships of the two-step algorithm are examined in greater detail below to address this problem. In this analysis, we discuss the results obtained using the $b_{b w}(555)$ values based on Buiteveld et al. (1994) with the salinity adjustment.

The relationship $b_{b}(555)$ vs. $R_{r s}(555)$ is significantly influenced by five data points collected in the Chilean upwelling waters, where $b_{b}(555)$ exceeded $0.003 \mathrm{~m}^{-1}$ (Fig. 8a). As a result, the regression line calculated from all data points provides an inadequate representation of the patterns present in the entire data set. This is clear even though the statistical characteristics of this fit have reasonably good values (Table 6). The relevant observation is that upwelling waters show reduced reflectance compared with the expectation from the general trend line for all non-upwelling data points. This effect can be further examined by noting that the upwelling values of $R_{r s}(555)$, which are close to or slightly above the value of $0.002 \mathrm{sr}^{-1}$, are associated with higher values of $b_{b}(555)$ compared to a station from the ANT-XXIII/1 cruise (PS69/027) with a similar value of $R_{r s}(555)$. This suggests that, in addition to differences in $b_{b}(555)$, there were also significant differences in the absorption coefficient $a$ (555) between the Chilean upwelling stations and the station PS69/027 (which is the southernmost station on the ANT-XXIII/1 cruise, located at $25.97^{\circ} \mathrm{S}, 9.37^{\circ} \mathrm{E}$ ). The absorption data confirm this expectation. Whereas $a(555)$ at PS69/027 was $0.063 \mathrm{~m}^{-1}$, the values at the upwelling stations ranged from about 0.09 to $0.107 \mathrm{~m}^{-1}$; higher by a factor of 1.4-1.7 compared with PS69/027. Importantly, very similar factors are found for $b_{b}(555)$ that was about $0.0023 \mathrm{~m}^{-1}$ at PS69/027 and $0.0033-0.0042 \mathrm{~m}^{-1}$ at the upwelling stations. Because $R_{r s}(\lambda)$ is driven primarily by the ratio $b_{b}(\lambda) /\left[a(\lambda)+b_{b}(\lambda)\right]$, and because $b_{b}(\lambda)$ is typically much smaller than $a(\lambda)$, similar parallel changes in $b_{b}(555)$ and $a(555)$ lead to the similar values of $R_{r s}(555)$ for the upwelling stations and the PS69/027 station seen in Fig. 8a. These results are further supported in Fig. 9, where $R_{r s}(555)$ plotted against $b_{b}(555) /\left[a(555)+b_{b}(555)\right]$ follow approximately one linear relationship, albeit some scatter in the data exists. Importantly, the three rightmost data points in Fig. 9 (two of which are BIOSOPE upwelling stations and one is PS69/027) are close to one another. We also note that $b_{b}(555)$ was never more than $3.8 \%$ of $a(555)$ in our data set, and that the highest $b_{b}(555) / a(555)$ was observed at the BIOSOPE upwelling station (UPW1).

The main conclusion from Fig. 8a is that the determination of a single empirical relationship of $b_{b}(555)$ vs. $R_{r s}(555)$ over a range of oceanic conditions is impossible. Similar $R_{r S}(555)$ values can be observed when large differences in $b_{b}(555)$ and POC occur. For the selected stations with similar $R_{r s}(555)$ in our data set, POC was $58 \mathrm{mg} \mathrm{m}^{-3}$ at the PS69/027 station and $150-270 \mathrm{mg} \mathrm{m}^{-3}$ at the upwelling stations (TChl- $a$ was also significantly different; $0.11 \mathrm{mg} \mathrm{m}^{-3}$ and $1-1.5 \mathrm{mg} \mathrm{m}^{-3}$, respectively). Comparable limitation for the direct empirical estimation of $b_{b}$ from $R_{r s}$ has been observed previously in the Southern Ocean (Stramski et al., 1999), where data collected within a bloom of Phaeocystis antarctica ( $\mathrm{POC}>800 \mathrm{mg} \mathrm{m}^{-3}$ ) were characterized by significantly higher backscattering coefficient compared to other data at similar $R_{r s}(555)$ values of $0.002-0.003 \mathrm{sr}^{-1}$. Such limitation is due to possible considerable effect of variation in $a(555)$ on $R_{r s}(555)$. This is seen for the entire data set presented in Fig. 8a, where the maximum-to-minimum ratio of $b_{b}(555)$ is about 3.9 , and the analogous ratio for $a(555)$ is 1.8 , which implies a significant effect of variation in $a(555)$ on $R_{r s}(555)$. With the upwelling stations excluded, however, these ratios are 2.4 for backscattering and 1.3 for absorption (or 1.7 and 1.08, respectively, if only the ANT-XXIII/1 data are considered). Because the data with upwelling stations excluded show smaller effect of $a(555)$, the estimation of $b_{b}(555)$ from $R_{r s}(555)$ is improved (see the statistics for Step 1 equation in Table 6). Therefore, the use of a single empirical relationship $b_{b}(555)$ vs. $R_{r s}(555)$ may perhaps be justifiable over a limited range of oceanic conditions in relatively clear waters where POC $\leq 100 \mathrm{mg} \mathrm{m}^{-3}$. 
Table 6. Summary of fitted equations and error statistics for the two-step empirical POC algorithm depicted in Fig. 8. Least squares linear regression analysis was applied to calculate the coefficients $E_{1}, E_{2}, F_{1}$, and $F_{2} . R^{2}$ is the determination coefficient, RMSE the root mean square error, MNB the mean normalized bias, NRMS the normalized root mean square error, and $N$ the number of observations (see Table 1 for statistical formulas). $b_{b}(555), b_{b p}(555)$, and $b_{b w}(555)$ are in $\mathrm{m}^{-1}$, POC is in $\mathrm{mg} \mathrm{m}^{-3}$, and $R_{r s}(555)$ in $\mathrm{sr}^{-1}$. The results were obtained with pure seawater backscattering values, $b_{b w}(555)$, calculated according to Buiteveld et al. (1994) with the salinity adjustment (see text for details). These values vary slightly in our data set with water temperature and salinity, but the average $b_{b w}(555)=8.748 \times 10^{-4} \mathrm{~m}^{-1} \mathrm{can}$ be used in the application of this two-step algorithm with no significant impact on its performance. For comparison, the results obtained with $b_{b w}(555)=9.22 \times 10^{-4} \mathrm{~m}^{-1}$ from Morel (1974) are also shown.

\begin{tabular}{ccccccccc}
\multicolumn{1}{l}{ Step 1 equation: $b_{b}(555)=E_{1} R_{r s}(555)+E_{2}$} & \multirow{2}{*}{$E_{1}$} & $E_{2}$ & $R^{2}$ & $\begin{array}{c}\text { RMSE } \\
{\left[\mathrm{m}^{-1}\right]}\end{array}$ & $\begin{array}{c}\text { MNB } \\
{[\%]}\end{array}$ & $\begin{array}{c}\text { NRMS } \\
{[\%]}\end{array}$ & $N$ \\
\hline All data & Buiteveld & 2.787 & -0.002792 & 0.783 & 0.0003254 & 1.48 & 17.38 & 51 \\
All data & Morel & 2.785 & -0.002794 & 0.783 & 0.0003251 & 1.48 & 17.41 & 51 \\
Upwelling data excluded & Buiteveld & 1.521 & -0.000843 & 0.689 & 0.0001671 & 1.24 & 11.89 & 46 \\
Upwelling data excluded & Morel & 1.520 & -0.000846 & 0.690 & 0.0001665 & 1.24 & 11.88 & 46 \\
\hline
\end{tabular}

\begin{tabular}{|c|c|c|c|c|c|c|c|c|}
\hline & $b_{b w}$ & $F_{1}$ & $F_{2}$ & $R^{2}$ & $\begin{array}{c}\text { RMSE } \\
{\left[\mathrm{mg} \mathrm{m}^{-3}\right]}\end{array}$ & $\begin{array}{c}\text { MNB } \\
{[\%]}\end{array}$ & $\begin{array}{c}\text { NRMS } \\
{[\%]}\end{array}$ & $N$ \\
\hline All data & Buiteveld & 70850.7 & -9.088 & 0.863 & 18.66 & 1.02 & 28.28 & 59 \\
\hline All data & Morel & 71002.0 & -5.500 & 0.863 & 18.62 & 1.16 & 27.99 & 59 \\
\hline Upwelling data excluded & Buiteveld & 53606.7 & 2.468 & 0.777 & 9.32 & 5.28 & 24.29 & 54 \\
\hline Upwelling data excluded & Morel & 53932.4 & 5.049 & 0.778 & 9.30 & 5.33 & 24.34 & 54 \\
\hline
\end{tabular}

\begin{tabular}{|c|c|c|c|c|c|c|}
\hline & $b_{b w}$ & $R^{2}$ & $\begin{array}{c}\text { RMSE } \\
{\left[\mathrm{mg} \mathrm{m}^{-3}\right]}\end{array}$ & $\begin{array}{c}\mathrm{MNB} \\
{[\%]}\end{array}$ & $\begin{array}{c}\text { NRMS } \\
{[\%]}\end{array}$ & $N$ \\
\hline All data & Buiteveld & 0.587 & 35.14 & 6.90 & 72.87 & 51 \\
\hline All data & Morel & 0.586 & 35.19 & 7.19 & 73.04 & 51 \\
\hline Upwelling data excluded & Buiteveld & 0.655 & 14.34 & 15.54 & 46.43 & 46 \\
\hline Upwelling data excluded & Morel & 0.653 & 14.38 & 15.73 & 46.71 & 46 \\
\hline
\end{tabular}

The second relationship of the two-step algorithm, POC vs. $b_{b p}(555)$, is depicted in Fig. 8b. In this case, several data points collected at upwelling stations with POC $\geq 150 \mathrm{mg} \mathrm{m}^{-3}$ show significant scatter but do not suggest a clearly different pattern compared with the remaining data. The relationship for the entire data set has acceptable error statistics with MNB of about $1 \%$ and NRMS of about $28 \%$ (Table 6). The removal of upwelling data from the analysis results in less steep slope; the effect similar to that seen in the POC vs. $c_{p}(660)$ relationship in Fig. 7. Although the fitted regression coefficients for POC vs. $b_{b p}(555)$ differ between the entire data set and the limited data set with upwelling stations excluded (Table 6), the adoption of a relationship based on all data would at this point appear reasonable, especially considering the limited number of our observations and their distribution with few data collected at inter- mediate and higher POC. However, one can generally expect that the POC vs. $b_{b p}(555)$, like any POC vs. IOP relationship, may undergo significant variations due to temporal and spatial variability in particulate assemblages of different oceanic regions. Such expectation is supported by earlier observations in the Southern Ocean where $b_{b p}(555)$ was typically higher in the Antarctic Polar Front Zone than in the Ross Sea at similar levels of POC (Stramski et al., 1999), indicating differences in the carbon-specific backscattering coefficient. A definitive judgment of whether the carbon-specific backscattering was different in the water bodies examined during BIOSOPE and ANT-XXIII/1 is difficult with our data but the discussion in Sect. 3.4 provides some insights into this question. 

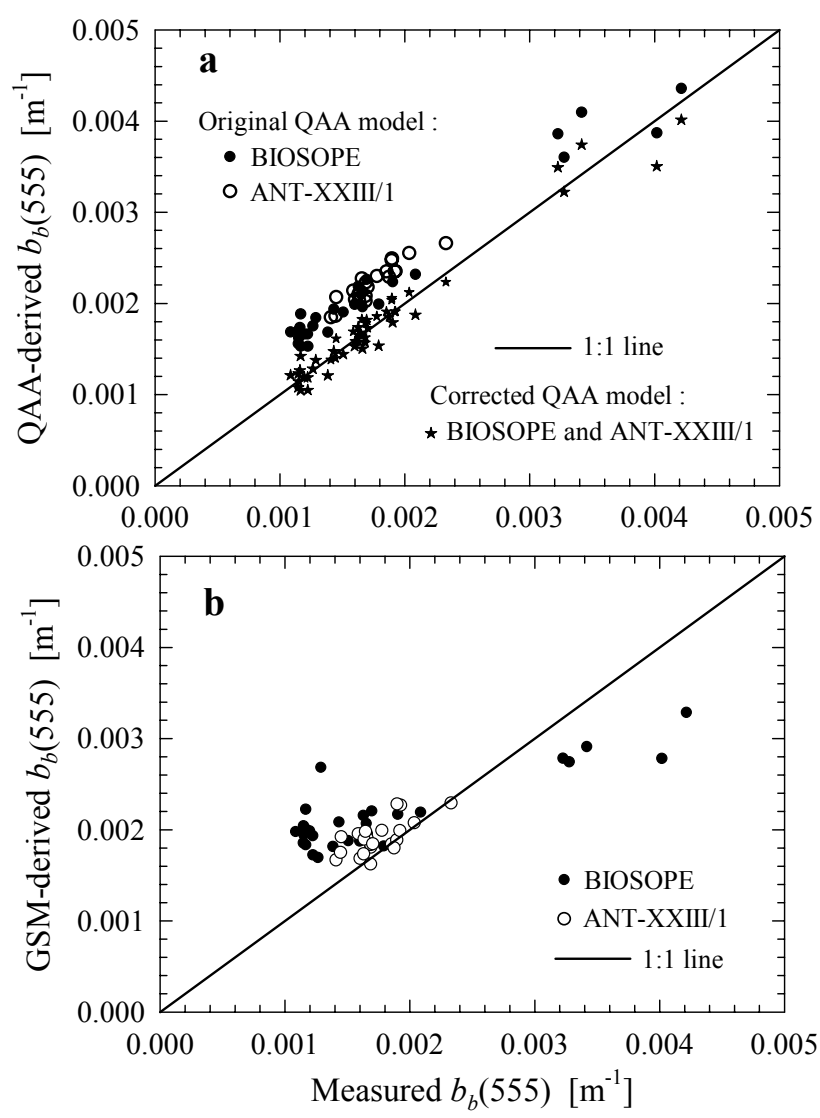

Fig. 10. Particulate backscattering coefficient, $b_{b}(555)$, derived from a semianalytical model as a function of measured $b_{b}(555)$ for (a) a semianalytical model of Lee et al. (2002) referred to as QAA, and (b) a semianalytical model of Garver and Siegel (1997) updated by Maritorena et al. (2002), referred to as GSM. Panel (a) shows the results for both the original QAA model and the corrected QAA model (see text and Table 7 for details). The results in panel (b) are for the GSM model.

\subsubsection{Two-step hybrid approach}

In addition to approaches based exclusively on empirical relationships, we have also examined a two-step approach referred to as a hybrid approach. In the hybrid approach we use a semianalytical model as a means for retrieving $b_{b}(555)$ from $R_{r s}(\lambda)$ in the first step of the algorithm. The second step of the hybrid algorithm is the same as described above, that is POC is derived from $b_{b p}(555)$ using our empirical relationship from Fig. 8b (see also Table 6).

We examined two semianalytical models that are currently used quite commonly in the area of ocean color research. The first model, referred to as the Quasi-Analytical Algorithm (QAA), was developed by Lee et al. (2002). The second model, referred to as the GSM model (for Garver-SiegelMaritorena), was initially developed by Garver and Siegel (1997) and later updated by Maritorena et al. (2002). For examining the QAA model we followed the procedure described in Lee et al. (2006) (Eqs. 10.2, 10.3, 10.6, and 10.7 in that reference). In brief, the diffuse attenuation coefficient for downwelling irradiance, $K_{d}(555)$, was first estimated from the measured MBR. Then, the absorption coefficient, $a(555)$, was obtained from the measured $R_{r s}(555)$ and the derived $K_{d}(555)$. Finally, the backscattering coefficient, $b_{b}(555)$, was obtained from the relationship between $R_{r s}(555)$ and the ratio $b_{b}(555) /\left[a(555)+b_{b}(555)\right]$. In the evaluation of the GSM model we utilized an IDL code (available at http://www.icess.ucsb.edu/OCisD/) with a standard set of parameters optimized for applications to offshore oceanic waters (see Table 2 in Maritorena et al., 2002). In particular, we first retrieved $b_{b p}(443)$ from $R_{r s}(\lambda)$ measured at five wavelengths: $412,443,490,510$, and $555 \mathrm{~nm}$. We then calculated $b_{b p}(555)$ using the spectral slope of $\eta=1.0337$ for the particulate backscattering (see Eq. $3 \mathrm{c}$ in Maritorena et al., 2002). The sum of $b_{b p}(555)$ and $b_{b w}(555)=0.000922$ $\mathrm{m}^{-1}$ yielded the GSM-derived $b_{b}(555)$. In this case we used $b_{b w}(555)$ from Morel (1974) because Morel's pure seawater backscattering values were used in the development of the GSM model.

Figure 10a compares the QAA-derived $b_{b}(555)$ with the measured $b_{b}(555)$. For our entire data set, the QAA provides a systematic overestimation of measured $b_{b}(555)$. This overestimation is characterized by a nearly constant offset over the examined range of conditions from the gyre to upwelling stations. The linear regression between the measured and QAA-derived $b_{b}(555)$ (not shown here) has a slope of about 1.05 (which is notably close to 1 ) and an intercept of $-0.0005541 \mathrm{~m}^{-1}\left(R^{2}=0.957, N=50\right)$. Using the original QAA-derived backscattering coefficient, $b_{b}$, original (555), as inputs to this regression function, we obtained new values of $b_{b}(555)$ referred to as the corrected QAA-derived backscattering coefficient, $b_{b \text {, corrected }}(555)$. These corrected values are in good agreement with the measurements (Fig. 10a). The error statistics for the derivation of $b_{b \text {,corrected }}(555)$ is very good as MNB is only about $0.4 \%$ and NRMS is $7.6 \%$ (Table 7). The errors, especially MNB, are obviously much higher for $b_{b \text {,original }}$ (555). Table 7 also demonstrates that the aggregate error statistics is quite satisfactory for the hybrid two-step POC algorithm, in which $b_{b \text {,corrected }}(555)$ is used. On the basis of our data set such POC algorithm has a small MNB of about $0.7 \%$. The NRMS of $33 \%$ is significant but still acceptable. Therefore, this type of algorithm has the potential for good performance. However, because the relatively good results were here obtained only after the application of considerable empirical correction (based on our field data) to the original QAA model, further improvements in semianalytical modeling are desirable. We verified, for example, that the estimates of absorption coefficient, $a(555)$, obtained with the QAA model were, on average, lower by about $8 \%$ than the measured $a(555)$ in our data set. These tests of absorption retrievals suggest that it was not the absorption component of the QAA model which caused the 
Table 7. Summary of error statistics for the two-step hybrid POC algorithm. In step $1, b_{b}(555)$ is derived from the Quasi-Analytical Algorithm (QAA) of Lee et al. (2002). Statistics for the original QAA model and for the corrected QAA model are shown. The corrected $b_{b}(555)$ was obtained from the original QAA-derived $b_{b}(555)$ using a linear relationship: $b_{b, \text { corrected }}(555)=1.049 b_{b \text {, original }}(555)-0.0005541$. Aggregate statistics for the hybrid two-step POC algorithm are also shown, where $b_{b}(555)$ is obtained in step 1 using the corrected QAA model, and the coefficients $F_{1}$ and $F_{2}$ are from the step 2 equation given in Table 6. $R^{2}$ is the determination coefficient, RMSE the root mean square error, MNB the mean normalized bias, NRMS the normalized root mean square error, and $N$ the number of observations (see Table 1 for statistical formulas). $b_{b}(555)$ is in $\mathrm{m}^{-1}$, POC is in $\mathrm{mg} \mathrm{m}^{-3}$, and the pure seawater backscattering, $b_{b w}(555)$, was calculated according to Buiteveld et al. (1994) with the salinity adjustment (see text for details).

Step 1: $b_{b}(555)$ calculated from QAA model

\begin{tabular}{cccccc}
\hline & $R^{2}$ & $\begin{array}{c}\text { RMSE } \\
{\left[\mathrm{m}^{-1}\right]}\end{array}$ & $\begin{array}{c}\text { MNB } \\
{[\%]}\end{array}$ & $\begin{array}{c}\text { NRMS } \\
{[\%]}\end{array}$ & $N$ \\
\hline Original QAA & 0.537 & 0.0004787 & 28.47 & 12.19 & 50 \\
Corrected QAA & 0.957 & 0.0001467 & 0.36 & 7.59 & 50 \\
\hline
\end{tabular}

Aggregate statistics for the two-step hybrid algorithm: POC $=F_{1}\left[b_{b, \text { corrected }}(555)-b_{b w}(555)\right]+F_{2}$

\begin{tabular}{ccccc}
\hline$R^{2}$ & $\begin{array}{c}\text { RMSE } \\
{\left[\mathrm{mg} \mathrm{m}^{-3}\right]}\end{array}$ & $\begin{array}{c}\text { MNB } \\
{[\%]}\end{array}$ & $\begin{array}{c}\text { NRMS } \\
{[\%]}\end{array}$ & $N$ \\
\hline 0.871 & 19.47 & 0.73 & 33.02 & 50 \\
\hline
\end{tabular}

retrievals of $b_{b}(555)$ to be systematically higher than the backscattering measurements.

The need for further improvements in semianalytical models is also supported by a comparison of GSM-derived $b_{b}(555)$ with measured $b_{b}(555)$ in Fig. $10 \mathrm{~b}$. Again we see that the semianalytical model does not provide consistently good agreement with the measurements. For our data set, the GSM model shows a tendency to overestimate the measured $b_{b}(555)$ at low values (especially at the gyre stations) and underestimate the measurements at higher values at the upwelling stations. Such biases that appear to depend on environmental conditions limit the usefulness of the GSM model in its present form in the development of POC algorithms. We note, however, that the GSM model showed significantly better performance for retrieving TChl- $a$ with our data set. In this case, the bias was small $(\mathrm{MNB}=-3 \%)$ although NRMS remained significant at about $35 \%$.

\subsection{Variability in particulate backscattering ratio}

The relationships between POC and IOPs, such as those presented in Figs. 7 and 8b, are variable in the ocean. The variability in these relationships can be attributed to two causes; first, variations in the characteristics of particulate assemblage which affect IOPs, such as the particle concentrations and distributions of particle size and refractive index within the assemblage, and second, variations in the distribution of organic carbon among the various particle types and particle size classes within an assemblage. Both Fig. 7 and $8 b$ show that the removal of the upwelling data from the analysis leads to a smaller slope of the POC vs. IOP relationships in our data set. A closer inspection of Fig. 8b also suggests that many non-upwelling BIOSOPE measurements are characterized by higher carbon-specific backscattering of particles than the ANT-XXIII/1 measurements. This is seen in that many BIOSOPE data are below and the ANTXXIII/1 data are above the regression fit (see the dashed line in Fig. 8b). For the non-upwelling data from BIOSOPE, the average value of the carbon-specific particulate backscattering coefficient, $b_{b p, \mathrm{POC}}^{*}(555)$, is $1.97 \times 10^{-5} \mathrm{~m}^{2}(\mathrm{mg} \mathrm{C})^{-1}$ $\left(\mathrm{SD}=4.6 \times 10^{-6}, N=29\right)$. For ANT-XXIII/1 the average $b_{b p, \mathrm{POC}}^{*}(555)$ is $1.66 \times 10^{-5} \mathrm{~m}^{2}(\mathrm{mg} \mathrm{C})^{-1} \quad\left(\mathrm{SD}=2.8 \times 10^{-6}\right.$, $N=25$ ).

Although these observations are subject to inevitable uncertainties in the determinations of POC and $b_{b p}$ in clear ocean waters, it is useful to tentatively test the possible differentiation in the carbon-specific backscattering between the two cruises by examining the particulate backscattering ratio, $\tilde{b}_{b p}=b_{b p}(555) / b_{p}(555)$. The parameter $\tilde{b}_{b p}$ describes the fraction of light scattered by particles in backward directions, and hence it is independent of particle concentration but is sensitive to physicochemical particle properties such as size and refractive index (e.g., Morel and Bricaud, 1986). The potential usefulness of $\tilde{b}_{b p}$ to study composition of marine particulate matter has been examined recently (Twardowski et al., 2001; Boss et al., 2004; Sullivan et al., 2005; Whitmire et al., 2007). Figure 11 compares the surface data of $\tilde{b}_{b p}$ plotted against POC from the BIOSOPE and ANT-XXIII/1 cruises. It is remarkable that the BIOSOPE values of $\tilde{b}_{b p}$ are higher than the ANT-XXIII/1 values. For the BIOSOPE data set the average $\tilde{b}_{b p}$ is 0.0104 , whereas for the ANT-XXIII/ 1 data set it is 0.0054 . The higher $\tilde{b}_{b p}$ can generally be associated with an increased role of small-sized particles contributing to $b_{b}$ (especially those $\leq 1-2 \mu \mathrm{m}$ ), an increase in the bulk refractive index of particles, or both. Unfortunately, detailed characterization of particle properties required for rigorous analysis of their effects on $\tilde{b}_{b p}$ are not easily or routinely acquired on oceanographic cruises.

Despite these limitations, we can explore the results in Fig. 11 in terms of available information about particle properties in the investigated waters. The data of POC:SPM collected on the BIOSOPE cruise (Fig. 2), the location of the BIOSOPE study area away from terrestrial sources, and low deposition of atmospheric particles suggest the dominance of organic particles. In contrast, some measurements in the Atlantic were likely made on water samples with significant contribution of terrigenous inorganic particles, which is 


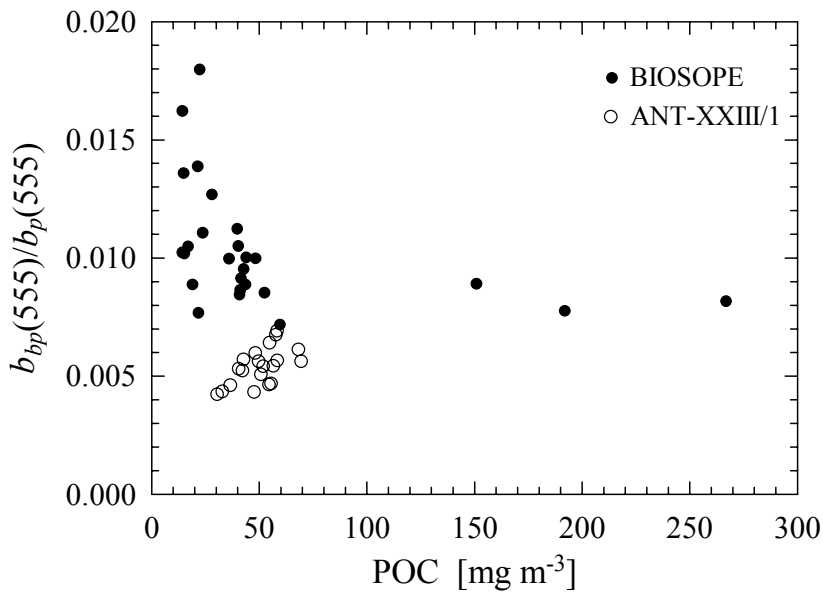

Fig. 11. Particulate backscattering ratio, $b_{b p}(555) / b_{p}(555)$, plotted as a function of surface concentration of particulate organic carbon, POC, for the BIOSOPE and ANT-XXIII/1 cruises.

indicated by larger range in POC:SPM including low values of this ratio on the ANT-XXIII/1 cruise (Fig. 2). A common assumption is that marine organic particles have generally lower refractive index (relative to water) than inorganic particles (Kerr, 1977; Aas, 1996). We must stress, however, the limitation of this common assumption, which is that the relatively low refractive index of organic particles can be assigned with certainty only to living biological cells that contain significant amount of water (i.e., the so-called "soft" particles). The calcifying algae are the noteworthy exception with higher refractive index because they produce calcite $\left(\mathrm{CaCO}_{3}\right)$ scales. The refractive index of non-living organic particles suspended in seawater is poorly understood, mainly because the water content of such particles remains poorly characterized. Nonetheless, if any differences in the bulk refractive index of particulate matter between the BIOSOPE and ANT-XXIII/1 data were to be hypothesized, one could speculate that at least some ANT-XXIII/1 data corresponding to presumably high inorganic contribution (i.e., the stations with the lowest POC:SPM in Fig. 2) would have the highest refractive index. However, the $\tilde{b}_{b p}$ values from ANT-XXIII/1 show relatively small range and are lower than BIOSOPE data, which would suggest that the potential variability in particle refractive index is not the major factor responsible for the differences in $\tilde{b}_{b p}$ between the cruises shown in Fig. 11.

From a refractive index perspective, it is also of interest to consider possible variability in biogenic calcite particles, mainly coccolithophore phytoplankton species and detached coccoliths, which have high refractive index. Balch et al. (1999) estimated that in typical nonbloom conditions suspended coccoliths may account for $10-20 \%$ of light backscattering, which indicates that calcite particles are generally an important scattering component in the ocean. The
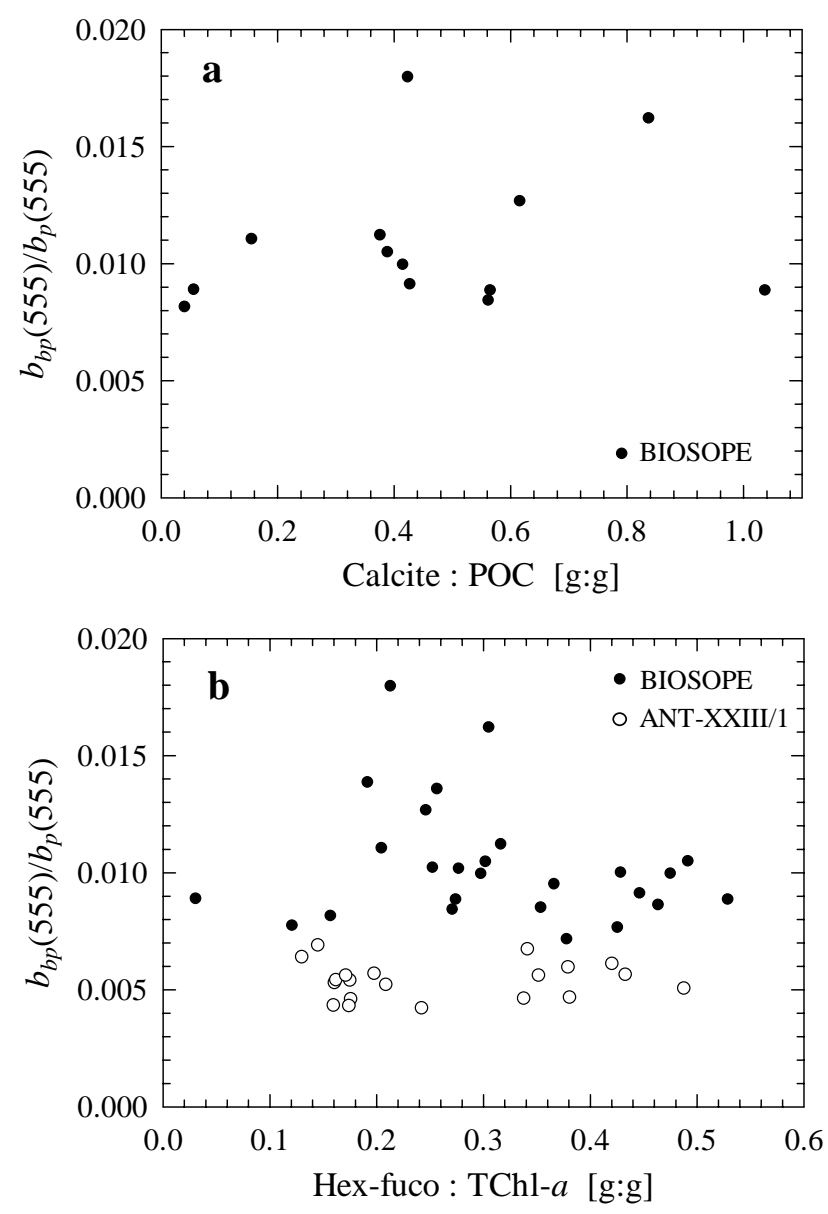

Fig. 12. Particulate backscattering ratio, $b_{b p}(555) / b_{p}(555)$, plotted as a function of (a) ratio of surface concentration of particulate calcite to POC for the BIOSOPE cruise, and (b) pigment ratio Hexfuco:TChl- $a$ in surface waters for the BIOSOPE and ANT-XXIII/1 cruises. The calcite and pigment data for BIOSOPE are taken from Beaufort et al. (2007) and Ras et al. (2007), respectively.

surface concentration of suspended calcite particles on the BIOSOPE cruise ranged from about 3 to $25 \mathrm{mg} \mathrm{CaCO}_{3} \mathrm{~m}^{-3}$ (Beaufort et al., 2007). The lowest values were observed in the gyre and the highest values in the transition zone between the eastern boundary of the gyre and the upwelling stations. These concentrations and the calcite-specific backscattering coefficient that was previously determined to be about $1.37 \times 10^{-5} \mathrm{~m}^{2}\left(\mathrm{mg} \mathrm{CaCO}_{3}\right)^{-1}$ (Balch et al., 1999, 2001) can be used to obtain estimates of the backscattering coefficient due to calcite particles. These estimates range from about $4 \times 10^{-5} \mathrm{~m}^{-1}$ in the gyre to $3.4 \times 10^{-4} \mathrm{~m}^{-1}$ in the transition zone between the gyre and upwelling area. The values of $b_{b p}(555)$ from measurements in the gyre were between about $2.1 \times 10^{-4}$ and $3.4 \times 10^{-4} \mathrm{~m}^{-1}$ and the higher values in the transition zone were between $1 \times 10^{-3}$ and $1.8 \times 10^{-3} \mathrm{~m}^{-1}$. These calculations suggest that calcite particles could have 
made a significant contribution to particulate backscattering from about $10 \%$ to over $30 \%$ at some BIOSOPE stations. Such contributions can, in turn, suggest an enhancement of the backscattering ratio due to highly refractive calcite particles. A tendency for $\tilde{b}_{b p}(555)$ to increase with the ratio of calcite concentration to POC concentration in surface waters is unclear for the 13 data pairs available from BIOSOPE, albeit cannot be completely ruled out (Fig. 12a). In this figure, the calcite:POC ratio may be considered as an approximate index for the contribution of calcite particles with high refractive index to the total pool of organic particles, which are characterized by a lower value of the bulk refractive index than that of calcite.

Similar estimation is not possible for ANT-XXIII/1 because no determinations of calcite concentration were made. We can, however, compare BIOSOPE and ANT-XXIII/1 in terms of the 19'-Hexanoyloxyfucoxanthin (Hex-fuco) pigment, which is often used as a diagnostic index for the presence of phytoplankton species from the group of Prymnesiophytes, to which coccolithophores belong (e.g., Vidussi et al., 2001; Ras et al., 2007). Although Hex-fuco is not a unique index of coccolithophores, the concentration of this pigment showed a similar pattern to calcite concentration along the BIOSOPE cruise track (Beaufort et al., 2007; Ras et al., 2007). The range of the pigment ratio Hex-fuco:TChl$a$ is similar for both cruises (with the exception of one data point from the Chilean shelf that has the lowest pigment ratio of 0.03 ) and $\tilde{b}_{b p}$ shows no tendency to increase with Hexfuco:TChl- $a$ (Fig. 12b). The lack of such tendency is also observed when $\tilde{b}_{b p}$ is plotted vs. Hex-fuco concentration (not shown). Thus these data provide no evidence that coccolithophores could have been responsible for enhanced $\tilde{b}_{b p}$ on BIOSOPE compared with ANT-XXIII/1.

Another factor that can contribute to the differences in $\tilde{b}_{b p}$ between BIOSOPE and ANT-XXIII/1 is the variation in particle size distribution (PSD). PSD data were acquired on BIOSOPE with a Beckman-Coulter Multisizer III equipped with a $30 \mu \mathrm{m}$ aperture tube and occasionally with a $20 \mu \mathrm{m}$ tube (Loisel et al., 2006). This instrument setup allowed us to size particles as small as $0.5-0.7 \mu \mathrm{m}$. One of the most important results obtained with the particle analysis was a steep slope of PSD, which was observed consistently in the submicrometer size range at oligotrophic and hyperoligotrophic BIOSOPE stations. The slope $(\xi)$ of the power function fit to the PSD data, or more specifically, the slope of the density function of the so-called Junge-type differential size distribution $F(D) \sim D^{-\xi}$, varied typically from 5 to 7 in the submicrometer range for surface samples (Loisel et al., 2006). For particles larger than $1 \mu \mathrm{m}, \xi$ was usually close to 4 (Stemmann et al., 2007), which is generally consistent with previous PSD data for marine particles (e.g., Bader, 1970).

The steep slopes in the submicrometer range suggest a very large contribution of small particles from colloidal size range to the overall concentration of particles. These smallsized particles are expected to make higher percent contri-

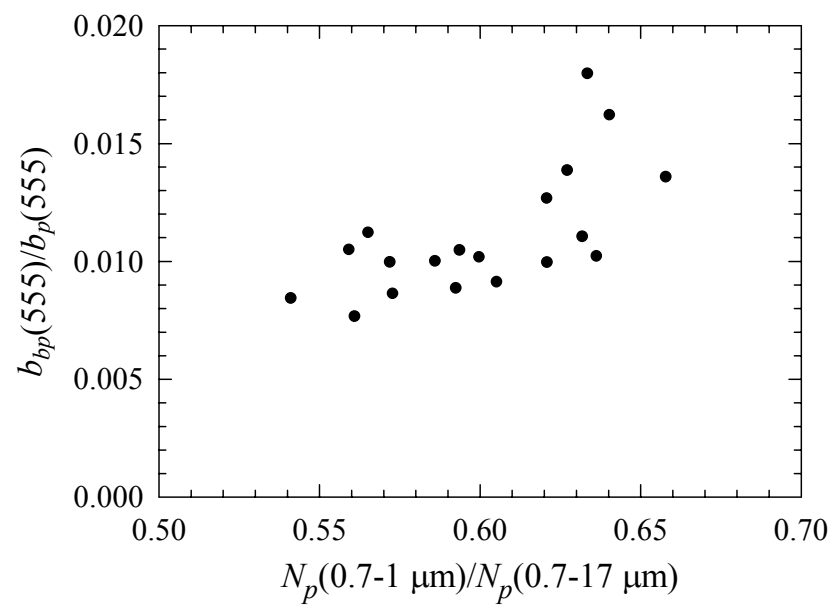

Fig. 13. Particulate backscattering ratio, $b_{b p}(555) / b_{p}(555)$, plotted as a function of the contribution of submicrometer particles to the total concentration of particles measured on the BIOSOPE cruise with a Beckman Coulter Multisizer III equipped with a $30-\mu \mathrm{m}$ aperture tube. The submicrometer particles are here represented by the concentration of particles, $N_{p}(0.7-1 \mu \mathrm{m})$, with equivalent diameter between 0.7 and $1 \mu \mathrm{m}$, and the total particle concentration, $N_{p}(0.7-$ $17 \mu \mathrm{m})$, refers to particles in the size range from 0.7 to $17 \mu \mathrm{m}$.

bution to particulate backscattering than to total particulate scattering, so the particulate backscattering ratio $\tilde{b}_{b p}$ is expected to increase with an increased contribution of small particles to total particle concentration (e.g., Stramski and Kiefer, 1991). The effect of an increase in $\tilde{b}_{b p}$ with increasing slope of PSD has been demonstrated explicitly with modeling results based on Mie scattering theory (Twardowski et al., 2001). According to those results, a particle assemblage that covers a broad range of sizes with a single slope $\xi$ somewhat steeper than 4 , can easily achieve the backscattering ratio $\tilde{b}_{b p}$ of about 0.01 or higher, even if the relative refractive index of particles is as low as 1.02. Therefore, it is conceivable that the PSDs with particularly steep slopes in the submicrometer range were at least partly responsible for the $\tilde{b}_{b p}$ values close to or above 0.01 in the BIOSOPE data set. For this data set, we observe a tendency for $\tilde{b}_{b p}$ to increase with increasing contribution of submicrometer particles to the total concentration of particles measured with BeckmanCoulter instrument, which is consistent with theoretical predictions (Fig. 13). Unfortunately, no PSD data are available from ANT-XXIII/1 so we cannot ascertain that less steep size distributions, especially in the small-size range, could be one of the main reasons for lower $\tilde{b}_{b p}$ on that cruise.

The question of whether potential errors in the determinations of $\tilde{b}_{b p}$ on the BIOSOPE and ANT-XXIII/1 cruises could lead to the differences shown in Fig. 11 also deserves consideration. We recall that the determinations of $b_{b p}(555)$ were made on both cruises with the same instrumentation, deployment methods, and procedures for data processing. 
Therefore, the possibility of significant bias in the $b_{b p}(555)$ estimates for one cruise relative to the other cruise is unlikely, albeit it cannot be excluded. Twardowski et al. (2007) indicated, for example, that measuring dark signal of the backscattering instruments under actual environmental conditions can be critical to ensure high accuracy, especially in very clear waters. We have not measured dark signals in situ; however, for the BIOSOPE cruise we have had available precruise and post-cruise manufacturer's calibrations, which include measurements of dark signals. We verified that the $\tilde{b}_{b p}$ values based on averaging pre-cruise and post-cruise calibrations (shown in Fig. 11) are higher, on average, by about $10 \%$ ( $\sim 20 \%$ at the most) than the values based on pre-cruise calibration. The lower pre-cruise calibration-based values of $\tilde{b}_{b p}$ on the BIOSOPE cruise would still be generally higher than $\tilde{b}_{b p}$ from ANT-XXIII/1.

The estimates of particulate scattering, $b_{p}(555)$, which also enter the calculations of $\tilde{b}_{b p}$, were obtained with different methods on the two cruises but again no particular source for bias significant enough to explain differences in Fig. 11 was identified in these determinations. We verified potential differences in the determinations of $b_{p}(555)$ from ac-9 measurements on BIOSOPE, which can arise from the application of different methods for correcting the absorption measurements for scattering error. For the surface data considered, the use of the proportional method, in which the scattering error is allowed to vary with wavelength (Zaneveld et al., 1994), would result in $b_{p}(555)$ values higher, on average, by only $3 \%$ compared with the values obtained with the simple wavelength-independent scattering correction based on the subtraction of absorption signal measured at $715 \mathrm{~nm}$. We recall that the latter method was used to generate the BIOSOPE data of $\tilde{b}_{b p}$ in Fig. 11 . The $\tilde{b}_{b p}$ values calculated with the proportional scattering correction method would be lower, on average, by about $2 \%$ (6\% at the most) than the data shown in Fig. 11. For the surface data from the BIOSOPE cruise, we have also verified that the estimates of $c-c_{w}$ from ac-9 tend to be higher than the estimates from C-Star transmissometer, which may result, at least partly, from a smaller acceptance angle of the ac-9 detector compared with that of the C-Star. The possible tendency for higher estimates of $b_{p}(555)$ from ac-9 compared with C-Star cannot explain the observed differences in $\tilde{b}_{b p}$ between the cruises as ac- 9 was used on BIOSOPE and C-Star on ANT-XXIII/1.

Whereas the differences in the backscattering ratio are generally consistent with differences in the carbon-specific backscattering coefficient between the Pacific and Atlantic data sets, the above discussion revealed difficulties in achieving an unambiguous interpretation of these results in terms of available data on particle characteristics and methodological issues. We were unable to identify any obvious methodological issues, but they cannot be ruled out as a possible source of the observed differences in $\tilde{b}_{b p}$ between the cruises. We note that our BIOSOPE estimates of surface $\tilde{b}_{b p}$ tend to be higher than average estimates of $\tilde{b}_{b p}$ presented in Twardowski et al. (2007) which were determined with a different methodology, namely from measurements with an ECOBB3 instrument (WET Labs, Inc.). These discrepancies underscore the considerable difficulties in accurate estimation of $b_{b p}$ in clear ocean waters. Nevertheless, the results from Fig. 11 are intriguing and require verification in future experiments. These results suggest differences in the physicochemical properties of particulate assemblages between the investigated Pacific and Atlantic waters. Such differences could have consequences to the relationships between POC and optical properties, which are seen to some extent in the present data set of POC vs. $b_{b p}$. These results thus emphasize the need for increased efforts in detailed characterization of particle properties in tandem with optical measurements taken during oceanographic cruises or experiments.

\section{Conclusions}

We have examined several approaches for estimating surface concentration of POC from optical measurements of remote-sensing reflectance, $R_{r s}(\lambda)$, using field data collected in tropical and subtropical surface waters of the eastern South Pacific and eastern Atlantic Oceans. The approach based on the direct empirical relationship between POC and the blue-to-green band ratio of reflectance, $R_{r s}\left(\lambda_{B}\right) / R_{r s}(555)$, promises reasonably good performance in the vast areas of the open ocean covering different provinces from hyperoligotrophic and oligotrophic waters within subtropical gyres to eutrophic coastal upwelling regimes characteristic of eastern ocean boundaries. The surface POC in our data set ranged from about $10 \mathrm{mg} \mathrm{m}^{-3}$ within the South Pacific Subtropical Gyre to $270 \mathrm{mg} \mathrm{m}^{-3}$ in Chilean upwelling waters. The measurements of POC:SPM, POC:TChl- $a$, phytoplankton pigments, and the backscattering ratio exhibit a significant range of variation, which indicates that our data set encompasses considerable variation in characteristics of oceanic particulate assemblages. Among the four band ratio algorithms examined, the best error statistics were found for power function fits to the data of POC vs. $R_{r s}(443) / R_{r s}(555)$ and POC vs. $R_{r s}(490) / R_{r s}(555)$ and these algorithms showed little sensitivity to whether or not the Chilean upwelling data were included in the analysis (Fig. 4 and Table 2).

We recommend that these algorithms can now be implemented for routine processing of ocean color satellite data to produce maps of surface POC within the global ocean. The judgment of whether to begin this processing with $R_{r s}(443) / R_{r s}(555)$ or $R_{r s}(490) / R_{r s}(555)$ (or perhaps both algorithms) should probably depend on current understanding of which of these band ratios is retrieved from satellite imagery with consistently better accuracy. Like many ocean bio-optical data products currently derived from satellite ocean color imagery, we expect that the surface POC from our proposed algorithms can have the status of an 
evaluation data product for continued work on algorithm development and refinements. There remain significant challenges to ensure consistent accuracy in POC retrievals from reflectance, for example the accurate field determinations of low levels of POC in very clear oligotrophic waters necessary for the algorithm development are themselves very difficult to achieve. We expect, however, that the accuracy of satellite retrievals of POC will be adequate for many applications such as the estimation of large scale or global budgets of surface POC. We also note that our proposed band ratio algorithms have similar regression coefficients to those previously determined from selected historical data sets that included 205 data pairs of POC and reflectance measured in several oceanic regions (Stramska and Stramski, 2005). This good comparison further supports our recommendation to begin processing of satellite ocean color imagery for estimating POC. At this time the use of our algorithms based on the BIOSOPE and ANT-XXIII/1 data appears preferable over additional consideration of historical data because our two data sets ensure a higher degree of consistency of methods used to collect field data for the algorithm development. Nevertheless, because the present amount and geographic coverage of simultaneously collected POC and reflectance data in the field is rather small, the exploration of historical data in the context of POC algorithm development is still worthwhile to pursue.

Other approaches for estimating POC from ocean reflectance that were examined in this study can be referred to as the two-step POC algorithms. In these approaches an IOP is first derived from an AOP (i.e., reflectance measurements) and then POC is derived from an IOP. The potential benefits of this two-step concept include flexibility for developing regionally and/or seasonally parameterized algorithms and insights into bio-optical variability that affects the algorithm relationships. One of our two-step empirical algorithms utilizes the particle beam attenuation coefficient, $c_{p}(660)$, as an IOP and the blue-to-green reflectance ratio, $R_{r s}\left(\lambda_{B}\right) / R_{r s}(555)$, as an AOP (Figs. 6 and 7, Tables 4 and 5). This algorithm may become particularly attractive if further research supports the robustness of the relationship $c_{p}(660)$ vs. $R_{r s}\left(\lambda_{B}\right) / R_{r s}(555)$ under various oceanic conditions. The second relationship of the algorithm, POC vs. $c_{p}(660)$, is generally expected to exhibit regional/seasonal variations due to varying properties of marine particulate assemblages, so it could be utilized as an algorithm component in regional/seasonal parameterizations. In our BIOSOPE and ANT-XXIII/1 data sets, however, such differentiation effects within the POC vs. $c_{p}(660)$ data were relatively small.

In the other two-step empirical algorithm, we utilized a single wavelength approach with the backscattering coefficients, $b_{b}(555)$ and $b_{b p}(555)$, as IOPs and remote-sensing reflectance, $R_{r s}(555)$, as an AOP (Fig. 8, Table 6). This algorithm showed less satisfactory error statistics than other algorithms examined in this study, particularly because of characteristically different patterns of upwelling and other (non-upwelling) data in the $b_{b}(555)$ vs. $R_{r s}(555)$ relationship. The variability in this relationship indicates a limitation for the use of this algorithm over a broad range of conditions. The potential variability in the step 2 relationship between POC and $b_{b p}(555)$ due to variations in the carbon-specific backscattering also cautions against indiscriminate use of this algorithm and highlights the need for further research to improve an understanding of IOPs in terms of physicochemical characteristics of particulate assemblages. Another limitation of the single-wavelength algorithm for satellite applications arises from the requirement for accurate satellite estimates of the absolute magnitude of $R_{r s}(555)$. This problem may not be as severe when reflectance band ratios are used as input to the algorithms. However, the two-step single-wavelength POC algorithm based on input $R_{r s}(555)$ has potential for decoupling the estimation of POC from chlorophyll- $a$ estimates that are obtained from empirical band ratio algorithms. Naturally, if the same reflectance band ratios are used as input to POC and chlorophyll algorithms, then both estimated variables are unrealistically forced to always covary. Thus, additional work on approaches such as that based on $R_{r s}(555)$ appears to be warranted as part of further research on POC algorithm development and refinements.

We anticipate that further research will address not only empirical correlational algorithms but also other approaches that may involve semianalytical and radiative transfer-based modeling. In this study, we examined two semianalytical algorithms for estimating IOPs from ocean reflectance; one referred to as QAA (Lee et al., 2002) and the other as GSM (Garver and Siegel, 1997; Maritorena et al., 2002). We tested the potential usefulness of QAA and GSM for deriving $b_{b}(555)$ from $R_{r s}(\lambda)$ as a first step of the two-step POC algorithm. When applied to our data set, both QAA- and GSM-derived $b_{b}(555)$ showed significant disagreement with the measured $b_{b}(555)$. Such results highlight general difficulties in the development of semianalytical models that perform consistently well in a variety of marine optical environments. Further improvements in these types of models will aid in efforts to refine POC algorithms.

Acknowledgements. This is a contribution of the BIOSOPE project in the eastern South Pacific as part of the LEFE-CYBER program, which was funded by the Centre National de la Recherche Scientifique (CNRS), the Institut des Sciences de l'Univers (INSU), the Centre National d'Etudes Spatiales (CNES) in France, the European Space Agency (ESA), the National Aeronautics and Space Administration (NASA) in USA, and the Natural Sciences and Engineering Research Council (NSERC) in Canada. The Alfred-Wegener Institute for Polar and Marine Research (Bremerhaven, Germany) kindly made it possible for us (D. S., R. A. R., S. K., M. S., and R. R.) to participate in the ANT-XXIII/1 cruise in the eastern Atlantic. This study was supported by NASA Ocean Biology and Biogeochemistry Program (NNG04GO02G awarded to D. S.) and NSF Chemical Oceanography Program (OCE-0324680 to D. S. and OCE-0324346 to M. S.). We thank D. Tailliez and 
C. Marec for assistance in CTD-rosette deployments and data processing on the BIOSOPE cruise, J. Ras for providing HPLC data, and L. Beaufort for calcite data from BIOSOPE. We also thank M. R. van der Loeff, the chief scientist of ANT-XXIII/1, for accommodating our research program on the cruise, K. Heymann for SPM determinations on ANT-XXIII/1, and G. Dieckmann and J. Schwarz for their assistance and for providing filtration equipment. The scientists, officers, and crews of R/V l'Atalante and R/V Polarstern are acknowledged for providing logistical support and their help onboard during the field work. The IDL code of the GSM semianalytical model was provided by S. Maritorena and D. Siegel, and M. Behrenfeld and W. Gardner provided valuable comments on the manuscript. The analysis of samples for particulate organic carbon was made at Marine Science Institute Analytical Laboratory, University of California at Santa Barbara. The HPLC analysis of pigment samples from the ANT-XXIII/1 cruise was made at Center for Hydro-Optics and Remote Sensing, San Diego State University. We dedicate this work to the memory of our friend and colleague S. Kaczmarek, who tragically passed away shortly after his participation in the ANT-XXIII/1 cruise.

Edited by: E. Boss

\section{References}

Aas, E.: Refractive index of phytoplankton derived from its metabolite composition, J. Plankton Res., 18, 2223-2249, 1996.

Antoine, D., Morel, A., Gordon, H. R., Banzon, V. F., and Evans, R. H.: Bridging ocean color observations of the 1980s and 2000s in search of long-term trends, J. Geophys. Res., 110, C06009, doi:10.1029/2004JC002620, 2005.

Bailey, S. W. and Werdell, P. J.: A multi-sensor approach for the on-orbit validation of ocean color satellite data, Remote Sens. Environ., 102, 12-23, 2006.

Bader, H.: The hyperbolic distribution of particle sizes, J. Geophys. Res., 75, 2822-2830, 1970.

Baker, E. T. and Lavelle, J. W.: The effect of particle size on the light attenuation coefficient of natural suspensions, J. Geophys. Res., 89, 8179-8203, 1984.

Balch, W. M., Drapeau, D. T., Cucci, T. L., Vaillancourt, R. D., Kilpatrick, K. A., and Fritz, J. J.: Optical backscattering by calcifying algae: Separating the contribution of particulate inorganic and organic carbon fractions, J. Geophys. Res., 104, 1541-1558, 1999.

Balch, W. M., Drapeau, D. T., Fritz, J. J., Bowler, B. C., and Nolan, J.: Optical backscattering in the Arabian Sea - continuous underway measurements of particulate inorganic and organic carbon, Deep-Sea Res. I, 48, 2423-2452, 2001.

Beaufort, L., Couapel, M., Buchet, N., and Claustre, H.: Calcite production by coccolithophores in the South East Pacific Ocean: from desert to jungle, Biogeosciences Discuss., 4, 3267-3299, 2007 ,

http://www.biogeosciences-discuss.net/4/3267/2007/.

Behrenfeld, M. and Boss, E.: Beam attenuation and chlorophyll concentrations as alternative optical indices of phytoplankton biomass, J. Mar. Res., 64, 431-451, 2006.

Behrenfeld, M. J., Boss, E., Siegel, D. A., and Shea, D. M.: Carbon-based ocean productivity and phytoplankton phys- iology from space, Global Biogeochem. Cy., 19, GB1006, doi:10.1029/2004GB002299, 2005.

Bianchi, T. S., Lambert, C., and Biggs, D. C.: Distribution of chlorophyll a and phaeopigments in the northwestern Gulf of Mexico: A comparison between fluorometric and highperformance liquid chromatography measurements, Bull. Mar. Sci., 51, 25-32, 1995.

Bishop, J. K. B.: The correction and suspended matter calibration of Sea Tech transmissometer data, Deep-Sea Res., 33, 121-134, 1986.

Bishop, J. K. B.: Transmissometer measurement of POC, Deep-Sea Res. I, 46, 353-369, 1999.

Boss, E. and Pegau, W. S.: The relationship of light scattering at an angle in the backward direction to the backscattering coefficient, Appl. Opt., 40, 5503-5507, 2001.

Boss, E., Pegau, W. S., Lee, M., Twardowski, M. S., Shybanov, E., Korotaev, G. and Baratange, F.: Particulate backscattering ratio at LEO 15 and its use to study particle composition and distribution, J. Geophys. Res., 109, C01014, doi: 10.1029/2002JC001514, 2004.

Boss, E., Twardowski, M. S., and Herring, S.: Shape of the particulate beam attenuation spectrum and its inversion to obtain the shape of the particulate size distribution, Appl. Opt., 40, 48854893, 2001.

Bricaud, A., Babin, M., Morel, A. and Claustre, H.: Variability in the chlorophyll-specific absorption coefficients of natural phytoplankton: Analysis and parameterization, J. Geophys. Res., 100, 13 321-13 332, 1995.

Bricaud, A., Morel, A. Babin, M., Allali, K., and Claustre, H.: Variations of light absorption by suspended particles with chlorophyll a concentration in oceanic (case 1) waters: Analysis and implications for bio-optical models, J. Geophys. Res., 103, $31033-$ $31044,1998$.

Bricaud, A., Morel, A., and Prieur, L.: Absorption by dissolved matter of the sea (yellow substance) in the UV and visible domains, Limnol. Oceanogr., 26, 43-53, 1981.

Buiteveld, H., Hakvoort, J. H. M., and Donze, M.: The optical properties of pure water, in: Ocean Optics XII, Proc. SPIE, Vol. 2258, edited by: Jaffe, J. S., SPIE, Bellingham, Washington, 174-183, 1994.

Campbell, J.W., Blaisdell, J. M., and Darzi, M.: Level-3 SeaWiFS Data Products: Spatial and Temporal Binning Algorithms, in: NASA Tech. Memo. 104566, Vol. 32, edited by: Hooker, S. B., Firestone, E. R., and Acker, J. G., NASA Goddard Space Flight Center, Greenbelt, Maryland, 73 pp., 1995.

Clarke, G. L., Ewing, G. C., and Lorenzen, C. J.: Spectra of backscattered light from the sea obtained from aircraft as a measure of chlorophyll concentration, Science, 167, 1119-1121, 1970.

Claustre, H., Morel, A., Babin, M., Cailliaou, C., Marie, D., Marty, J.-C., Taillez, D., and Vaulot, D.: Variability in particle attenuation and chlorophyll fluorescence in the tropical Pacific: Scales, patterns, and biogeochemical implications, J. Geophys. Res., 104, 3401-3422, 1999.

Claustre, H., Sciandra, A., and Vaulot, D.: Introduction to the special section Bio-optical and biogeochemical conditions in the South East Pacific in late 2004: the BIOSOPE program, Biogeosciences Discuss., 5, 605-640, 2008, http://www.biogeosciences-discuss.net/5/605/2008/. 
Copin-Montégut, G.: Matiére en suspension dans les eaux de mer: répartition, composition chimique, origine et évolution. Ph.D. thesis. Laboratoire de Physique et Chimie Marines, Université Pierre et Marie Curie, 173 pp., 1980.

Dana, D. R. and Maffione, R. A.: Determining the backward scattering coefficient with fixed-angle backscattering sensors - Revisited, Ocean Optics XVI, Santa Fe, New Mexico, November 18-22, 2002.

Doxaran, D., Froidefond, J.-M., and Castaing, P.: A reflectance band ratio used to estimate suspended matter concentrations in sediment-dominated coastal waters, Int. J. Remote Sens., 23, 5079-5085, 2002.

DuRand, M. D., Green, R. E.., Sosik, H. M., and Olson, R. J.: Diel variations in optical properties of Micromonas pusilas (Prasinophyceae), J. Phycol., 38, 1132-1142, 2002.

Farinato, R. S. and Roswell, R. L.: New values of the light scattering depolarization and anisotropy of water, J. Chem. Phys., 65, 593-595, 1975

Franz, B. A., Werdell, P. J., Meister, G., Bailey, S. W., Eplee Jr., R. E., Feldman, G. C., Kwiatkowska, E., McClain, C. R., Patt, F. S., and Thomas, D.: The continuity of ocean color measurements from SeaWiFS to MODIS, in: Earth Observing Systems X, Proc. SPIE, 5882, edited by: Butler, J. J., SPIE, Bellingham, Washington, 13 pp., 2005.

Gardner, W. D., Biscaye, P. E., Zaneveld, J. R. V., and Richardson, M. J.: Calibration and comparison of the LDGO nephelometer and the OSU transmisometer on the Nova Scotian Rise, Mar. Geol., 66, 323-344, 1985.

Gardner, W. D., Mishonov, A. V., and Richardson, M. J.: Global POC concentrations from in-situ and satellite data, Deep-Sea Res. II, 53, 718-740, 2006.

Gardner, W. D., Richardson, M. J., Carlson, C. A., Hansell, D., and Mishonov, A. V.: Determining true particulate organic carbon: bottles, pumps and methodologies, Deep-Sea Res. II, 50, 655674, 2003.

Gardner, W. D., Richardson, M. J., and Smith, W. O.: Seasonal patterns of water column particulate organic carbon and fluxes in the Ross Sea, Antarctica, Deep-Sea Res. II, 47, 3423-3449, 2000.

Gardner, W. D., Walsh, I. D., and Richardson, M. J.: Biophysical forcing of particle production and distribution during a spring bloom in the North Atlantic, Deep Sea Res. II, 40, 171-195, 1993.

Garver, S. and Siegel, D. A.: Inherent optical property inversion of ocean color spectra and its biogeochemical interpretation. I. Time series from the Sargasso Sea, J. Geophys. Res., 102, 18607 $18625,1997$.

Garver, S., Siegel, D. A., and Mitchell, B. G.: Variability in nearsurface particulate absorption spectra: What can a satellite ocean color imager see?, Limnol. Oceanogr., 39, 1349-1367, 1994.

Gordon, H. R. and Morel, A.: Remote assessment of ocean color for interpretation of satellite visible imagery $-\mathrm{A}$ review, Lecture notes on coastal and estuarine studies, Springer-Verlag, New York, 1983.

Grob, C., Ulloa, O., Claustre, H., Huot, Y., Alarcon, G, and Marie, D.: Contribution of picoplankton to the total particulate organic carbon concentration in the eastern South Pacific, Biogeosciences, 4, 837-852, 2007,

http://www.biogeosciences.net/4/837/2007/.
Gundersen, J. S., Gardner, W. D., Richardson, M. J., and Walsh, I. D.: Effects of monsoons on the seasonal and spatial distribution of POC and chlorophyll in the Arabian Sea, Deep-Sea Res. II, 45, 2103-2132, 1998.

Holm-Hansen, O., Lorenzen, C. J., Holmes, R. W., and Strickland, J. D. H.: Fluorometric determination of chlorophyll, J. Cons. Int. Expl. Mer, 30, 3-15, 1965.

Honjo, S., Dymond, J., Collier, R., and Manganini, S. J.: Export production of particles to the interior of the equatorial Pacific Ocean during the 1992 EqPac experiment, Deep-Sea Res. II, 42, 831-870, 1995.

Jonasz, M. and Fournier, G. R.: Light Scattering by Particles in Water, Theoretical and Experimental Foundations, Elsevier, Amsterdam, 2007

Kerr, P. F.: Optical Mineralogy, Fourth Edition, McGraw-Hill, New York, 1977.

Knap, A., Michaels, A., Close, A., Ducklow, H., and Dickson, A. (Eds.): Protocols for the Joint Global Ocean Flux Study (JGOFS) Core Measurements, JGOFS Report Nr. 19 (Reprint of the IOC Manuals and Guides No. 29, UNESCO, Paris, 1994), 170 pp., 1996.

Lee, Z. P., Carder, K. L., and Arnone, R. A.: Deriving inherent optical properties from water color: a multiband quasi-analytical algorithm for optically deep waters, Appl. Opt., 41, 5755-5772, 2002.

Lee, Z. P., Carder, K. L., and Arnone, R. A.: The quasi-analytical algorithm, in: Remote Sensing of Inherent Optical Properties: Fundamentals, Tests of Algorithms, and Applications, IOCCG Report Number 5, edited by: Lee, Z. P., International OceanColour Coordinating Group, Dartmouth, Canada, 73-79, 2006.

Loisel, H., Bosc, E., Stramski, D., Qubelkheir, K., and Deschamps, P.-Y.: Seasonal variability of the backscattering coefficient in the Mediterranean Sea based on satellite SeaWiFS imagery, Geophys. Res. Lett., 28, 4203-4206, 2001.

Loisel, H. and Morel, A.: Light scattering and chlorophyll concentration in case 1 waters: A reexamination, Limnol. Oceanogr. 43, 847-858, 1998.

Loisel, H., Nicolas, J.-M., Deschamps, P.-Y., and Frouin, R.: Seasonal and inter-annual variability of particulate organic matter in the global ocean, Geophys. Res. Lett., 29(24), 2196, doi:10.1029/2002GL015948, 2002.

Loisel, H., Nicolas, J.-M., Sciandra, A., Stramski, D., and A. Poteau, A.: Spectral dependency of optical backscattering by marine particles from satellite remote sensing of the global ocean, J. Geophys. Res., 111, C09024, doi:10.1029/2005JC003367, 2006.

Longhurst, A. R.: Ecological Geography of the Sea, Academic Press, San Diego, California, 1998

Longhurst, A. R. and Harrison, W. G.: The biological pump: Profiles of plankton production and consumption in the upper ocean, Prog. Oceanogr., 22, 47-123, 1989.

Maffione, R. A. and Dana, D. R.: Instruments and methods for measuring the backward-scattering coefficient of ocean waters, Appl Opt., 36, 6057-6067, 1997.

Maritorena, S., Siegel, D. A., and Peterson, A. R.: Optimization of a semianalytical ocean color model for global-scale applications, Appl. Opt., 41, 2705-2714, 2002.

Marra, J., Langdon, C., and Knudson, C. A.: Primary production, water column changes, and the demise of a Phaeocystis bloom at 
the Marine Light-Mixed Layer site $\left(59^{\circ} \mathrm{N}, 21^{\circ} \mathrm{W}\right)$ in the northeast Atlantic Ocean, J. Geophys. Res., 100, 6633-6067, 1995.

Menzel, D. W.: Particulate organic carbon in the deep sea, DeepSea Res. I, 14, 229-238, 1966.

Milliman, J. D.: Production and accumulation of calcium carbonate in the ocean: budget of a nonsteady state, Global Biogeochem. Cy., 7, 927-957, 1993.

Mishonov, A. V., Gardner, W. D, and Richardson, M. J.: Remote sensing and surface POC concentration in the South Atlantic, Deep Sea Res. II, 50, 2997-3015, 2003.

Mobley, C. D.: Light and Water. Radiative Transfer in Natural Waters, Academic Press, San Diego, California, 1994.

Montagnes, D. J., Berges, J. A., Harrison, P. J., and Taylor, F. J. R.: Estimation of carbon, nitrogen, protein, and chlorophyll a from volume in marine phytoplankton, Limnol. Oceanogr. 39, 10441060, 1994.

Moran, S. B., Charette, M. A., Pike, S. M., and Wicklund, C. A.: Differences in seawater particulate organic carbon concentration in samples collected using small- and large-volume methods: the importance of DOC adsorption to the filter blank, Mar. Chem., 67, 33-42, 1999.

Morel, A.: Optical properties of pure water and pure sea water, in: Optical Aspects of Oceanography, edited by: Jerlov, N. G. and Steeman-Nielsen, E., Academic Press, New York, 1-24, 1974.

Morel, A.: Optical modeling of the upper ocean in relation to its biogenous matter content (case I waters), J. Geophys. Res., 93, 10749-10768, 1988.

Morel, A. and Bricaud, A.: Inherent optical properties of algal cells including picoplankton: theoretical and experimental results, in: Photosynthetic Picoplankton, Can. Bull. Fish. Aquat. Sci., 214, edited by: Platt, T. and Li, W. K. W., Dept. Fish. Oceans, Ottawa, Canada, 521-559, 1986.

Morel, A., Gentili, B., Claustre, H., Babin, M., Bricaud, A., Ras, J., and Tièche, F.: Optical properties of the "clearest" natural waters, Limnol. Oceanogr., 52, 217-229, 2007.

Morel, A. and Maritorena, S.: Bio-optical properties of oceanic waters: A reappraisal, J. Geophys. Res., 106, 7163-7180, 2001.

Morel, A., and Prieur, L.: Analysis of variations in ocean color, Limnol. Oceanogr., 22, 709-722, 1977.

Mueller, J. L., Fargion, G. S., and McClain, C. R. (Eds.): Ocean Optics Protocols for Satellite Ocean Color Sensor Validation, Revision 4, Volume III: Radiometric Measurements and Data Analysis Protocols, NASA/TM-2003-211621/Rev4-Vol. III, NASA Goddard Space Flight Center, Greenbelt, Maryland, 78 pp., 2003.

Myers, J. S. and Miller, R. L.: Optical airborne remote sensing, in: Remote Sensing of Coastal Aquatic Waters, edited by: Miller, R. L., Del Castillo, C. E., and McKee, B. A., Springer, Dordrecht, Netherlands, 51-67, 2005.

O'Reilly, J. E., Maritorena, S., Mitchell, B. G., Siegel, D. A., Carder, K. L., Garver, S. A., Kahru, M., and McClain, C. R.: Ocean color chlorophyll algorithms for SeaWiFS, J. Geophys. Res., 103, 24 937-24 953, 1998.

O'Reilly, J. E., Maritorena, S., Siegel, D. A., et al: Ocean Color Chlorophyll a Algorithms for SeaWiFS, OC2, and OC4: Version 4, in: SeaWiFS Postlaunch Technical Report Series, Vol. 11, SeaWiFS Postlaunch Calibration and Validation Analyses, Part 3, NASA/TM-2000-206892, Vol. 11, edited by: Hooker, S. B. and Firestone, E. R., NASA, Greenbelt, Maryland, 9-27, 2000.
Pabi, S. and Arrigo, K. R.: Satellite estimation of marine particulate carbon in waters dominated by different phytoplankton taxa, J. Geophys. Res., 110, C10018, doi:10.1029/2005JC003137, 2006.

Parsons, T. R., Maita, Y., and Lalli, C. M.: A Manual of Chemical and Biological Methods for Seawater Analysis, Elsevier, New York, 1984.

Platt, T. and Sathyendranath, S.: Oceanic primary production: Estimation by remote sensing at local and regional scales, Science, 241, 1613-1620, 1988.

Ras, J., Claustre, H., and Uitz, J.: Spatial variability of phytoplankton pigment distributions in the Subtropical South Pacific Ocean: comparison between in situ and predicted data, Biogeosciences Discuss., 4, 3409-3451, 2007, http://www.biogeosciences-discuss.net/4/3409/2007/.

Reynolds R. A., Stramski D., and Mitchell, B. G.: A chlorophylldependent semianalytical model derived from field measurements of absorption and backscattering coefficients within the Southern Ocean, J. Geophys. Res., 106, 7125-7138, 2001.

Robinson, I. S.: Measuring Oceans from Space: The Principles and Methods of Satellite Oceanography, Springer-Praxis, Chichester, UK, 2004.

Roesler, C. S. and Boss, E.: Spectral beam attenuation coefficient retrieved from ocean color inversion, Geophys. Res. Lett., 30(9), 1468, doi:10.1029/2002GL016185, 2003.

Röttgers, R. and Doerffer, R.: Measurements of optical absorption by chromophoric dissolved organic matter using a point-source integrating-cavity absorption meter, Limnol. Oceanogr. Methods, 5, 126-135, 2007.

Röttgers, R., Schönfeld, W., Kipp, P.-R., and Doerffer, R.: Practical test of a point-source integrating-cavity absorption meter: the performance of different collector assemblies, Appl. Opt., 44, 5549-5560, 2005.

Sarthou, G., Baker, A. R., Blain, S., Achterberg, E. P., Boye, M., Bowie, A. R., Croot, P., Laan, P., de Baar, H. J. W., Jickells, T. D., and Worsfold, P. J.: Atmospheric iron deposition and sea-surface dissolved iron concentrations in the eastern Atlantic Ocean, Deep-Sea Res. I, 50, 1339-1352, 2003.

Shifrin, K. S.: Physical Optics of Ocean Water, American Institute of Physics, New York, 1988.

Siegel, D. A., Dickey, T. D., Washburn, L., Hamilton, M. K., and Mitchell, B. G.: Optical determination of particulate abundance and production variations in the oligotrophic ocean, Deep-Sea Res., 36, 211-222, 1989.

Smith, R. C. and Baker, K. S.: The bio-optical state of ocean waters and remote sensing, Limnol. Oceanogr., 23, 247-259, 1978.

Sokal, R. R. and Rohlf, F. J.: Biometry: The Principals and Practice of Statistics in Biological Research, Third Edition, W. H. Freeman and Company, New York, 1995.

Spinrad, R. W.: A calibration diagram of specific beam attenuation, J. Geophys. Res., 91, 7761-7764, 1986.

Stemmann, L., Eloire, D., Sciandra, A., Jackson, G. A., Guidi, L., Picheral, M, and Gorsky, G.: Volume distribution for particles between $3.5 \mu \mathrm{m}$ and $2000 \mu \mathrm{m}$ in the upper $200 \mathrm{~m}$ region of the South Pacific Gyre, Biogeosciences Discuss., 3377-3407, 2007.

Stramska, M. and Stramski, D.: Variability of particulate organic carbon concentration in the north polar Atlantic based on ocean color observations with Sea-viewing Wide Fieldof-View Sensor (SeaWiFS), J. Geophys. Res., 111, C09003, doi:10.1029/2004JC002762, 2005. 
Stramska, M., Stramski, D., Kaczmarek, S., Allison, D. B., and Schwarz, J.: Seasonal and regional differentiation of bio-optical properties within the north polar Atlantic, J. Geophys. Res., 111, C08003, doi:10.1029/2005JC003293, 2006.

Stramski, D.: Refractive index of planktonic cells as a measure of cellular carbon and chlorophyll a content, Deep-Sea Res. I, 46, 335-351, 1999.

Stramski, D. and Kiefer, D. A.: Light scattering by microorganisms in the open ocean, Prog. Oceanogr., 28, 343-383, 1991.

Stramski, D. and Morel, A.: Optical properties of photosynthetic picoplankton in different physiological states as affected by growth irradiance, Deep-Sea Res., 37, 245-266, 1990.

Stramski, D. and Reynolds, R. A.: Diel variations in the optical properties of a marine diatom, Limnol. Oceanogr., 38, 13471364, 1993.

Stramski, D., Reynolds, R. A., Kahru, M., and Mitchell, B. G.: Estimation of particulate organic carbon in the ocean from satellite remote sensing, Science, 285, 239-242, 1999.

Stramski, D. and Tȩgowski, J: Effects of intermittent entrainment of air bubbles by breaking wind waves on ocean reflectance and underwater light field, J. Geophys. Res., 106, 31 345-31 360, 2001.

Stumpf, R. P. and Pennock, J. R.: Calibration of a general optical equation for remote sensing of suspended sediments in a moderately turbid estuary, J. Geophys. Res., 94, 14 363-14 371, 1989.

Sullivan, J. M., Twardowski, M. S., Donaghay, P. L., and Freeman, S. A.: Use of optical scattering to discriminate particle types in coastal waters, Appl. Opt., 44, 1667-1680, 2005.

Terrill, E. J., Melville, W. K., and Stramski, D.: Bubble entrainment by breaking waves and their influence on optical scattering in the upper ocean, J. Geophys. Res., 106, 16815-16 823, 2001.

Trees, C. C., Bidigare, R. R., Karl, D. M., Van Heukelem, L., and Dore, J.: Fluorometric chlorophyll a: Sampling, laboratory methods, and data analysis protocols, in: Ocean Optics Protocols for Satellite Ocean Color Sensor Validation, NASA/TM-2002210004/Rev3-Vol2, edited by: Mueller, J. L. and Fargion, G. S., NASA Goddard Space Flight Center, Greenbelt, Maryland, 269283, 2002.

Twardowski, M. S., Boss, E., Macdonald, J. B., Pegau, W. S., Barnard, A. H., and Zaneveld, J. R. V.: A model for estimating bulk refractive index from the optical backscattering ratio and the implications for understanding particle composition in case I and case II waters, J. Geophys. Res., 106, 14 129-14 142, 2001.

Twardowski, M. S., Claustre, H., Freeman, S. A., Stramski, D., and Huot, Y.: Optical backscattering properties of the "clearest" natural waters, Biogeosciences, 4, 1041-1058, 2007, http://www.biogeosciences.net/4/1041/2007/.

Twardowski, M. S., Lewis, M., Barnard, A., and Zaneveld, J.R.V.: In-water instrumentation and platforms for ocean color remote sensing applications, in: Remote Sensing of Coastal Aquatic Waters, edited by: Miller, R. L., Del Castillo, C. E., and McKee, B. A., Springer, Dordrecht, Netherlands, 69-100, 2005.
Twardowski, M. S., Sullivan, J. M., Donaghay, P. L., and Zaneveld, J. R. V.: Microscale quantification of the absorption by dissolved and particulate material in coastal waters with an ac-9, Atmos. Ocean. Technol., 16, 691-707, 1999.

Van der Linde, D. W.: Protocol for determination of total suspended matter in oceans and coastal zones, Technical Note No. 1.98.182, CEC-JRC, Ispra, Italy, 8 pp., 1998.

Van Heukelem L. and Thomas, C. S.: Computer-assisted highperformance liquid chromatography method development with applications to the isolation and analysis of phytoplankton pigments, J. Chromatogr. A, 910, 31-49, 2001.

Verity, P. G., Robertson, C. Y., Tronzo, C. R., Andrews, M. G., Nelson, J. R., and M. E. Sieracki, M. E.: Relationships between cell volume and the carbon and nitrogen content of marine photosynthetic nanoplankton, Limnol. Oceanogr., 37, 1434-1446, 1992.

Vidussi, F., Claustre, H., Manca, B. B., Luchetta, A., and Marty, J. C.: Phytoplankton pigment distribution in relation to upper thermocline circulation in the eastern Mediterranean Sea during winter, J. Geophys. Res., 106, 19939-19956, 2001.

Villafane, V., Helbling, W., and Holm-Hansen, O.: Phytoplankton around Elephant Island, Antarctica, Polar Biol., 13, 183-191, 1993.

Volk, T. and Hoffert, M. I.: Ocean carbon pumps: Analysis of relative strengths and efficiencies in ocean-driven atmospheric $\mathrm{CO} 2$ changes, in: The Carbon Cycle and Atmospheric CO2: Natural Variations Archean to Present, Geophys. Monogr. Ser., Vol. 32, edited by: Sundquist, E. T. and Broecker, W. S., AGU, Washington, D.C., 99-110, 1985.

Voss, K. J.: A spectral model of the beam attenuation coefficient in the ocean and coastal areas, Limnol. Oceanogr., 37, 501-509, 1992.

Whitmire, A. L., Boss, E., Cowles, T. J., and Pegau, W. S.: Spectral variability of the particulate backscattering ratio, Opt. Exp., 15, 7019-7031, 2007.

Yoder, A. Y., McClain, C. R., Feldman, G. C., and Esaias, W. E.: Annual cycles of phytoplankton chlorophyll concentrations in the global ocean: A satellite view, Global Biogeochem. Cy., 7, 181-193, 1993.

Zaneveld, J. R. V.: Variation of optical sea parameters with depth, in: Optics of the Sea (Interface and In-water Transmission and Imagery), Lecture Series, Vol. 61, NATO, 2.3-1-2.3-22, 1973.

Zaneveld, J. R. V., Kitchen, J. C., and Moore, C. M.: The scattering error correction of reflecting-tube absorption meters, in: Ocean Optics XII, Proc. SPIE, Vol. 2258, edited by: Jaffe, J. S., Bellingham, Washington, 44-55, 1994. 